ISSN: 0213-2079 - ISSN electrónico: 2386-3889

DOI: https://doi.org/10.14201/shhmo2018401427460

\title{
EL MINISTERIO DE HACIENDA EN PELIGRO: CONFLICTOS POLÍTICOS ACERCA DEL GOBIERNO DE LA HACIENDA EN 1740
}

\section{The Ministry of Finance in Danger. Political Conflicts around the Right Government of Finances in 1740}

\author{
Anne DUBET \\ Universidad Blaise Pascal, Clermont-Ferrand \\ Correo-e: anne.dubet@univ-bpclermont.fr
}

RESUMEN: Estudiamos una etapa de crisis en la construcción de un modelo institucional de gobierno de la Hacienda, centrándonos en la actividad de la Junta de Hacienda (1740). Es el punto más agudo de un conflicto generado después de la muerte de Patiño entre los responsables de la «distribución de caudales del rey». Asimismo, la Junta de Hacienda pretende resolver las dificultades causadas por la suspensión de pagos de 1739, restableciendo la confianza de la gente de negocios. Ambas preocupaciones confluyen en una propuesta institucional original -aunque avocada al fracaso- que tiene poco que ver con los ideales del gobierno colegial. Más allá de la forma de las instituciones estudiadas, el examen de la argumentación de los actores en conflicto permite reconstruir el significado político de sus proyectos.

Palabras clave: Ministro de Hacienda; Junta de Hacienda; Tesorería General; Crédito; Fernando Verdes Montenegro; cardenal Molina.

ABSTRACT: We study a stage of crisis in the construction of an institutional model of government of Finances, focusing on the activity of the Junta de Hacienda (1740). It is the most acute point of a conflict generated after Patiño's death among the Ministers in charge of the «distribution of flows» of the king. Likewise, the Junta tries to solve the difficulties caused by the suspension of payments of 1739, restoring the confidence of businessmen. Both concerns 
lead to an original institutional project-though it's a failure- different from the ideals of collegial government. Beyond the form of the institutions, the study of the argumentation of the people helps to reconstruct the political meaning of their projects.

Key words: Finance Minister; Junta de Hacienda; Treasury General; Credit; Fernando Verdes Montenegro; Cardinal Molina.

La expresión «reformismo borbónico» supone que los cambios políticoinstitucionales iniciados desde el advenimiento de Felipe $\mathrm{V}$ se articulan en torno a un proyecto homogéneo y coherente de la dinastía. Su eje es la imposición de un modo de gobierno orientado a la ejecución de las órdenes y no solo a la obediencia; según sus promotores, para que se afirme la autoridad real, los procedimientos «gubernativos» deben primar sobre los judiciales; como consecuencia, los ministros comisionados por el rey deben ejercer una influencia creciente, a expensas de los órganos colegiales dominados por letrados. El énfasis en esta coherencia permite afirmar que el cambio no se limita al reinado de Carlos III. Sin embargo, varios historiadores señalan la pluralidad de los proyectos de los reformadores para las instituciones de gobierno ${ }^{1}$ y su propensión a encontrar compromisos con grupos de poder y órganos existentes ${ }^{2}$. Otros señalan las continuidades entre el proceso reformador del reinado de Carlos II y el de Felipe $\mathrm{V}^{3}$ o reparan en las afinidades entre los proyectos de borbónicos y austracistas ${ }^{4}$. Matizan así la unidad y la originalidad del reformismo borbónico.

1. Sin ánimo de exhaustividad, cabe mencionar el debate entre «civilistas» y promotores de la presencia de los militares en empleos de gobierno (GIMÉnEz LóPEZ, E.: «El debate civilismomilitarismo y el régimen de Nueva Planta en la España del siglo XviıI», Cuadernos de Historia Moderna, 15, 1994, pp. 41-75), las disyuntivas sobre la organización de las Secretarías del Despacho (una síntesis en Dedieu, J. P.: Après le roi. Essai sur l'effondrement de la monarchie espagnole, Casa de Velázquez, Madrid, 2010, pp. 61-68) o la forma de las intendencias (AввAD, F. y Ozanam, D.: Les intendants espagnols du XVIIIe siècle. Madrid, Casa de Velázquez, 1992).

2. Por ejemplo, en las formas de colaboración entra la «vía de los Consejos» y la «vía reservada». CASTRO, C. de: El Consejo de Castilla en la historia de España (1621-1760). Madrid, Centro de Estudios Constitucionales, 2015. Peralta Ruiz, V.: Patrones, clientes y amigos. El poder burocrático indiano en la España del siglo XVIII. Madrid, CSIC, 2006.

3. MuÑoz Rodríguez, J. D.: «El superintendente austriaco y el intendente borbónico. La evolución de un modelo de gestión de los recursos fiscales en la Monarquía hispánica», en Dubet, A. y Ruiz Ibáñez, J. J. (eds.): Las monarquías española y francesa (siglos XVI-XVIII). ¿Dos modelos políticos?, Casa de Velázquez, 2010, pp. 130-141.

4. IÑurritegui Rodríguez, J. M.: Gobernar la ocasión. Preludio político de la Nueva Planta de 1707. Madrid, Centro de Estudios Políticos y Constitucionales, 2008. Quirós 
Quisiera abundar en esta línea examinando un conflicto en torno a las formas del gobierno de la Hacienda real de la España peninsular. El examen del proceso de construcción de estas al principio del siglo lleva a insistir en el carácter conflictivo de un cambio que, lejos de ser cumulativo y progresivo, está hecho de vaivenes y rupturas. Los reformadores de la Hacienda que contribuyeron a la creación de nuevas instituciones -la Tesorería General, las Secretarías del Despacho, en particular de la Hacienda, y las intendencias durante la Guerra de Sucesión y la década posterior ${ }^{5}-$ no tardan en dividirse. Así, las formas dadas a estas instituciones y, como corolario, las relaciones mantenidas con la gente de negocios, son fruto de compromisos entre los promotores de alternativas distintas, además de la negociación con grupos más reacios al cambio ${ }^{6}$. José Patiño, al acceder a la Secretaría de Hacienda en octubre de 1726, parece poner fin a una década de inestabilidad. Procede a una reforma de la planta de la Tesorería General cuyos principales puntos son la reafirmación de que la mayor parte de los gastos del rey se deben hacer en ella o en su nombre y su subordinación al secretario del Despacho de la Hacienda, único secretarios, de ahora en adelante, en poder comunicarle órdenes de gasto, a exclusión de los demás Ministros ${ }^{7}$. Se abre un período de estabilidad institucional que se puede explicar por la duración de Patiño en el cargo, el apoyo de la reina ${ }^{8}$ y la ausencia de conflicto con los demás secretarios responsables de gastos cuantiosos ya que Patiño ocupa la Secretaría de Marina e Indias y su hermano ocupa la de Guerra hasta su muerte, sucediéndole el propio Patiño. El Secretario de Hacienda es además Superintendente General de la Hacienda y Gobernador del Consejo de Hacienda. Reúne así los tres empleos que, según Patiño y uno de sus predecesores, el marqués de Campoflorido, debían constituir al que llamaban

Rosado, R.: «Las secretarías de Estado y Guerra en la monarquía de Carlos VI: ¿vías hacia una planta ejecutiva?», en Pérez Álvarez, M. J. y Martín García, A. (eds.): Actas de la XI reunión cientifica de la FEHM, Granada, Universidad de Granada, 2012, pp. 1581-1592.

5. Dedieu, J. P.: «La Nueva Planta en su contexto. Las reformas del aparato del Estado en el reinado de Felipe V», Manuscrits, 18, 2000, pp. 113-139.

6. Dubet, A.: La Hacienda Real de la Nueva Planta (1713-1726), entre fraude y buen gobierno. El caso Verdes Montenegro y las reformas de la Hacienda. Madrid, Fondo de Cultura Económica, 2015.

7. Sobre los inicios de la Tesorería General, véase Dubet, La Hacienda, y la bibliografía citada. Las expresiones «Tesorería General» y «Tesorería Mayor» designan dos modelos de control financiero y de relación con el mundo del crédito distintos hasta 1726. A partir de la reforma de Patiño, aunque la planta elegida por este es la de la Tesorería Mayor, se usan los dos sintagmas de forma indiferente, incluso en un mismo documento.

8. Vázquez Gestal, P.: Una nueva majestad. Felipe V, Isabel de Farnesio y la identidad de la monarquía (1700-1729). Madrid, Marcial Pons, 2013. 
Ministro de Hacienda ${ }^{9}$. No se vuelve a reformar la planta de la Tesorería antes del ejercicio de Campillo, en marzo de 1743, y entonces se reafirma la autoridad del ministro sobre ella.

Esta evolución, no obstante, resultó más conflictiva y sinuosa. Los Secretarios de Hacienda posteriores a Patiño, menos influyentes, se enfrentan a una oposición variopinta para mantener la organización descrita. 1740 es un año de culminación de los conflictos. Corresponde al ministerio de Fernando Verdes Montenegro (enero de 1740-febrero de 1741) y a la actividad de la Junta de Hacienda (febrero de 17401741) instituida a iniciativa de su protector, el cardenal Gaspar de Molina, Gobernador del Consejo de Castilla. Interesa examinar este momento para comprender el proceso de cambio de las formas de gobierno de la monarquía. En la discusión armada en aquel entonces en torno a las facultades respectivas del Secretario de Hacienda y los demás secretarios y al estatuto de la Tesorería General, están en juego los fines del gobierno de la Hacienda y la relación entre el monarca y sus secretarios. Las líneas del conflicto no se pueden resumir a la oposición entre partidarios del gobierno colegial y defensores del gobierno ministerial. Precisamente, las estrategias de los actores les llevan a proceder a otras asociaciones, en un bricolaje que invalida las clasificaciones demasiado sistemáticas. Su inventiva es el punto de partida de las recomposiciones posteriores, pudiéndose considerar los ministerios de Campillo y Ensenada más como el fruto de esta crisis de 1740 que como el de la continuidad de la acción de Patiño.

9. Dubet, A.: «Entre razón y ciencia de la Hacienda: la conflictiva construcción de un modelo de buen gobierno de la Real Hacienda en España en la primera mitad del siglo xviıI», Espacio, Tiempo y Forma, 28, 2015, pp. 187-209. En el citado artículo se estudia la aparición del sintagma «Ministro de Hacienda», de uso frecuente a partir de la década de los 1720 bajo la pluma de los que promueven la concentración de las competencias de gobierno de la real Hacienda en las manos de un solo individuo. Se usa asimismo «Ministerio», aunque su uso es menos frecuente que el de Ministro. Lo emplea a menudo Alejandro de Vega (art. cit., nota 36; véase también el art. cit. en la nota 13 de este trabajo). En el período que nos interesa aquí, aparece el término en cartas del marqués de Torrenueva a Sebastián de la Cuadra (a 10/08/1737, AGS, SSH, leg. 408), de José Campillo a José del Prado Güemes (a 27/02/1741, AGS, SSH, leg. 227), cédulas de Felipe V a Campillo (a 05/03/1741, AHN, FC-MH, libro 8014, núm. 690) y a La Ensenada (a 19/05/1743, AHN, FC-MH, libro 8015, fols. 43-46), etc. Sobre el «Ministro de Guerra», véase Glesener, T., «Reformar el corporativismo militar: la acción política del duque de Montemar como ministro de guerra (1737-1741)», en prensa. En este trabajo, usamos «ministro» sin mayúscula cuando su significado es el usual en el Antiguo Régimen (el que «sirve y ministra», según el Diccionario de la Real Academia, 1734, p. 572) y «Ministro» con mayúscula cuando los actores se refieren al «Ministro de Hacienda», al de Marina y al de Guerra. 
ANNE DUBET

EL MINISTERIO DE HACIENDA EN PELIGRO:

CONFLICTOS POLÍTICOS ACERCA DEL GOBIERNO DE LA HACIENDA EN 1740

\section{LA HERENCIA DEL CONFLICTO}

El ministerio de Verdes Montenegro dura trece meses (13 de enero de 1740-27 de febrero de 1741$)^{10}$. Interesó poco a los historiadores. Pablo Fernández Albaladejo indica que corresponde a un momento de unión con los hombres de negocios que obstaculizaría cualquier intento de reforma ${ }^{11}$. Parecen confirmarlo la estrategia de la Junta de Hacienda, menos reformadora que la Junta de Medios anterior ${ }^{12}$, y su hostilidad a la suspensión de pagos de 1739, como señala Francisco Andújar Castillo ${ }^{13}$. Los comentarios de Alejandro de Vega y José Campillo, estudiados por Delgado Barrado, alimentan la misma lectura. Vega, buen conocedor de las formas del manejo de la Hacienda y protegido de Juan Bautista de Iturralde (marzo de 1739-enero de 1740), predecesor de Verdes Montenegro en la Secretaría del Despacho de Hacienda ${ }^{14}$, lamenta su evicción, atribuyéndola -sin duda con razón a la influencia de Molina: Verdes Montenegro, «hechura del cardenal», «solo trató de su conservación y, variando enteramente el sistema, volvió el desorden de la Hacienda a su primitivo estado». La realización esencial de la Junta de Hacienda sería en efecto el conjunto de iniciativas fiscales adoptadas a fines de 1740, una política que Vega opone a la de «reducir gastos» de la Junta de Medios que asesoró sucesivamente al marqués de Torrenueva (noviembre de 1736-marzo de 1739) y a Iturralde, cuyo secretario fue Vega ${ }^{15}$. Campillo escribe al final del ministerio de Verdes Montenegro, esperando sucederle. Concentra su crítica en los mismos puntos, con argumentos diversos ${ }^{16} \mathrm{y}$ con tanta más saña cuanto que, en enero de

10. A $13 / 01 / 1740$, le confiere el gobierno del Consejo de Hacienda y sus tribunales, la Secretaría del Despacho de Hacienda y la Superintendencia de rentas generales, la distribución de los caudales y la comisión de juez privativo de los valimientos (AHN, E, leg. 6401-1). Se describen sus competencias de Superintendente en cédulas de 17 y 18/01/1740 (AHN, FC, libro 8014, núm. 661 y AHN, E, libro 800). El rey comunica su dimisión al cardenal Molina a 27/02/1741 (AHN, E, leg. 6401-1).

11. Fernández Albaladejo, P.: «El decreto de suspensión de pagos de 1739: análisis e implicaciones», Moneda y crédito, 142, 2007, pp. 51-85.

12. Delgado Barrado, J. M.: Aquiles y Teseos. Bosquejos del reformismo borbónico (1701-1759). Universidad de Granada, Universidad de Jaén, 2007, pp. 87-110. Dubet, A.: «La suspensión de pagos de 1739: ¿una medida de «buen gobierno» de la Hacienda?», Espacio, Tiempo y Forma, 30, 2017, pp. 19-56.

13. Andújar Castillo, F.: «La hacienda real en tiempos de crisis: 1739-1741», en Cortés Peña, A. L., López-Guadalupe Muñoz, M. L. y Sánchez-Montes González, F. (eds.): Estudios en homenaje al profesor José Szmolka Clares. Granada, 2005, pp. 537-546.

14. Delgado Barrado: 2007, pp. 87-110. Dubet, A.: «El gobierno de la Hacienda real de Felipe V y los interesados según Alejandro de Vega», Tiempos Modernos, 30, 2015/1. http:// www.tiemposmodernos.org/tm3/index.php/tm/article/view/430/461.

15. «Trata de los gastos». AHN, E, libro 916, fol. 165.

16. Delgado Barrado: Aquiles..., pp. 44-48 y 204. 
1740, ya fue candidato al empleo ${ }^{17}$. Finalmente, Julio Caro Baroja cita un autor anónimo quien denuncia la multiplicación intempestiva de juntas y la desagregación paralela de la Tesorería Mayor ${ }^{18}$. En suma, el año de gobierno de Verdes Montenegro sería el de la desconstrucción del proyecto de Campoflorido, Patiño o Iturralde: unidad de la decisión en un Ministro que monopoliza la distribución de caudales, unidad del manejo en la Tesorería Mayor, esfuerzo por imponerse a los hombres de negocios. Pero dos elementos son disonantes, un vivo conflicto entre el Ministro de Guerra, el duque de Montemar (marzo de 1737-octubre de 1741), y Verdes Montenegro, mencionado por Andújar Castillo, y el que Campillo no renuncia al valimiento del $10 \%$, como señala Delgado Barrado. El estudio de la Junta de Hacienda permite observar que no solo está en juego la política fiscal, reparando en la complejidad de la acción de Verdes Montenegro. El Ministro parece buscar mantener un equilibrio improbable entre la satisfacción que debe dar a su protector, hostil a la preeminencia del Ministro de Hacienda, y su convicción de que la Tesorería Mayor, bajo la autoridad de este, es la mejor forma de organizar la distribución. Esta posición recuerda la que adoptara en 1724, durante su primer ejercicio de Secretario de Hacienda ${ }^{19}$.

Para entender la discusión en torno al buen gobierno de la Hacienda en 1740, conviene recordar la situación heredada. La dominan las tensiones surgidas desde la muerte de Patiño y el descrédito consecutivo a la suspensión de pagos decidida por Iturralde a 21 de marzo de 1739. No solo el equilibrio institucional fortalecido por Patiño está tambaleándose, sino que se ponen en tela de juicio las bases del crédito de la monarquía. Estas descansan en la unión estrecha entre la Tesorería Mayor y el Ministro de Hacienda y en la prevalencia de un control político de este sobre la distribución de los fondos ${ }^{20}$. La Tesorería Mayor o General es una oficina compuesta de varias agencias, la caja de Madrid y las tesorerías particulares de ejércitos, que «refunden» sus cuentas en una sola preparada por los contadores del Tesorero General. Desde 1713, las cajas de las principales rentas del rey en España, aunque son exteriores a la Tesorería, hacen sus gastos en nombre de

17. Lo relata su compañero Astraudi, en Rodríguez Villa, A.: Patiño y Campillo. Madrid, Sucesores de Rivadeneyra, 1882, caps. 8-9. Campillo ya fue candidato infeliz en marzo de 1739 (BNE, ms 2559).

18. Caro Baroja, J.: La hora navarra del XVIII (personas, familias, negocios e ideas). Pamplona, Comunidad Foral de Navarra, 1985, 1. ${ }^{\text {a }}$ ed. 1969.

19. Dubet: La Hacienda..., 2. ${ }^{\mathrm{a}}$ parte y 3 . $^{\mathrm{a}}$ parte, caps. 1 y 3 .

20. Los dos párrafos siguientes se basan en Dubet: La Hacienda ..., passim. S. Solbes Ferri precisa las modalidades de la relación entre la Tesorería General y la renta del tabaco («El delicado tránsito entre recaudación de rentas y ejecución del gasto. La renta del tabaco y la Tesorería General a mediados del siglo XviII», en prensa). 
ella. Esta novedad significa que, a partir de aquel entonces, cada administrador o arrendador de rentas que hace un pago en nombre del Tesorero Mayor debe informar a este de la operación, para poder obtener de él los abonos indispensables a su rendición de cuentas. Por esta razón, en 1726, los contemporáneos comparan a la Tesorería con una Veeduría General de la Hacienda, considerándola -con razón- como un instrumento de centralización del control contable. Como complemento, las Contadurías Generales de Valores y de la Distribución creadas en 1717 deben comparar la documentación contable del Tesorero General con la de todo responsable del manejo de caudales del rey. Al mismo tiempo, el Tesorero General se ha convertido en el principal emisor de «efectos» de papel en España: los boletines y las cartas de pago provisionales del Tesorero, los vales de resto y los harébuenos de su cajero son los principales papeles en circulación. Esta capacidad de producción de efectos descansa en un acuerdo con los recaudadores de rentas, en particular los arrendadores de las rentas provinciales, creadas en asociación con esta versión de la Tesorería en 1713. Ministros como Campoflorido y Patiño se esforzaron por construir una relación de confianza con ellos. Esta es necesaria, porque la principal fuerza de la Tesorería General, su capacidad de hacer pagos en toda España mediante la emisión de cartas de pago provisionales «sobre» tal o cual arrendador, tesorero o depositario del rey, puede convertirse en una debilidad: cuando se multiplican los atrasos, los acreedores ceden «viejos créditos» por debajo de su precio a los individuos que les pueden dar dinero en efectivo. La ambivalencia de la Tesorería reside aquí: aunque la emisión de efectos es la razón de ser de la Tesorería, los gobernantes temen que se arme un tráfico incontrolado. En efecto, los que ganan en él son los que tienen suficiente poder y legitimidad para obtener que la Hacienda real les abone estos efectos en su valor nominal. El último elemento es el Ministro de Hacienda. Campoflorido y Patiño no lo concibieron solo como la única vía de la autoridad del rey sobre el Tesorero General. También es el responsable del crédito: elige a los contratistas, negociando con ellos las formas de su reembolso; además, desde fines de 1726, le pertenece la decisión de pagar las deudas de los Tesoreros Generales salientes.

La eficacia del edificio se evalúa en términos políticos, más que económicos. Se trata de saber si la Tesorería y las cajas exteriores a ella hicieron los pagos en los momentos y lugares decididos por el Ministro de Hacienda. Su buena marcha depende de la capacidad que tiene este de establecer una colaboración fluida con sus colegas más gastadores, los Ministros de Guerra y de Marina; en caso de conflicto, necesita del apoyo del rey. Asimismo, es decisiva la calidad de su relación con el Tesorero. El Ministro no puede trabajar sin las informaciones dadas por este y su red de relaciones entre los responsables de rentas y los hombres de negocios. A la inversa, la salud del Tesorero depende de las decisiones del Ministro en la 
elección de arrendadores o asentistas, así como de su buena disposición a la hora de comunicarle sus decisiones relativas a la distribución de fondos, ya que el Ministro puede mandar a responsables de rentas que hagan pagos en nombre del Tesorero sin que este se entere antes de verificarse el pago. Así, el buen funcionamiento de la Tesorería depende de los hombres, entrando en juego su capacidad para trabajar juntos, sus concepciones del buen gobierno y lo que los actores llaman su virtud y celo.

La presión de la guerra en los años 1730 puso el edificio a prueba. Patiño y Torrenueva llevaron la maquinaria del crédito a sus límites iniciando, hacia 1734, una forma nueva de «negociaciones», el «beneficio», es decir, la venta de cartas de pago provisionales del tesorero en la plaza madrileña, para obtener «anticipaciones». La operación no se hizo en la caja de la Tesorería en Madrid. Se confió a Martín de Herce, «agente principal de la Tesorería General de la Guerra», con la anuencia del Ministro y su Tesorero General. Herce, Tesorero Principal de la renta del tabaco desde 1738, y tal vez ya interesado en la administración de esta jugosa renta anteriormente, se valió en particular de ella para reembolsar las anticipaciones. Uno de los mayores prestamistas fue Ventura de Pinedo, a la vez Director de la renta del tabaco y Tesorero de la renta de Cruzada. La política de Iturralde fue ante todo una reacción contra estos acuerdos que, como explicó, debilitaban al crédito real y a los arrendadores de rentas provinciales, entre los cuales figuraban varios navarros, amigos y socios suyos. Así justificó la suspensión de pagos de 21 de marzo, arguyendo que buscaba distinguir entre los que procuraron ganancias ilícitas en el «beneficio» de efectos y los prestamistas honestos, como los arrendadores de rentas provinciales. La destitución de los responsables de la renta del tabaco, perseguidos por fraude, y la sustitución del Tesorero General por un hombre de confianza, el conde de Moriana, eran una medida de retorsión. Al mismo tiempo, reafirmó la vía reservada y su control de una Tesorería General única ${ }^{21}$. La otra cara del saneamiento de la Hacienda se definía en el marco de la Junta de Medios. Uno de sus principales objetos fue el control del nivel del gasto militar y del de las Casas Reales ${ }^{22}$. Para sostener tal política, el apoyo del rey era indispensable, tanto frente a los acreedores defraudados como frente a los demás Ministros. Molina, cuya virulenta oposición a la Junta de Medios fue analizada por Delgado Barrado, podría entrar en la primera categoría ${ }^{23}$. Además de su rechazo de Gobernador de Castilla y prelado a las prerrogativas del Ministro de Hacienda, pudieron pesar sus

21. Hasta aquí, resumo Dubet: «La suspensión...».

22. Delgado Barrado: Aquiles..., pp. 93-94, 101-102.

23. Delgado Barrado: Aquiles..., pp. 93-94, 195-203. 
intereses en la renta de la Cruzada, ya que era su Comisario General ${ }^{24}$. Por otra parte, Torrenueva e Iturralde solo ocuparon la Secretaría de Hacienda, lo que abrió un segundo frente de conflicto. Iturralde se opuso al nuevo Ministro de Guerra, el duque de Montemar, quien se resistía a entregarle un «reglamento» del gasto de guerra $^{25}$. Ahora bien, al contrario de Patiño, Torrenueva e Iturralde no se beneficiaron del franco apoyo del rey. Este se negó a aceptar un proyecto de suspensión de pagos sometido por Torrenueva ${ }^{26}$, motivando una amarga queja del Ministro ${ }^{27}$. Aunque Felipe V sí aceptó la que propuso Iturralde, este pronto entendió que no podía contar con él frente a Montemar ${ }^{28}$. Según Vega, sus ofertas de dimisión, en diciembre de 1740, son la respuesta a la presión de sus adversarios ${ }^{29}$. Al sucederle como Ministro de Hacienda, Verdes Montenegro debe encarar la pérdida efectiva de influencia del Secretario de Hacienda frente a sus colegas del despacho, aunque sus facultades oficiales permanecen intactas. Asimismo, se espera que dé satisfacción a los acreedores del rey cuyos créditos fueron suspendidos en 1739, en un contexto de rápido alza del gasto militar provocado por la Guerra de la Oreja de Jenkins.

\section{Restablecimiento De LA FE PÚblica y PEQUEÑAS VENGANZAS}

Verdes Montenegro reúne los tres empleos de Hacienda, así como la distribución de los fondos, la facultad de «poner cobro y transigir los débitos que me pertenezcan y todas las demás facultades que por varias resoluciones y decretos puse al cuidado del citado marqués de Murillo, sin diferencia alguna» ${ }^{30}$. Ya

24. Vega le sospecha de administrarla con excesiva autonomía. AHN, E, lib. 916, fols. $141-142$ y 154.

25. Dubet: «La suspensión...». En la Casa Real, Montemar se enfrentó a la brigada de carabineros que, para escapar a la fiscalización del ministro de Guerra, solicitaba que sus gastos siguieran haciéndose dentro de la Tesorería General y que sus negocios se trataran en la Secretaría del Despacho de Guerra (GLESENER: «Reformar...»). Este conflicto podría haber alimentado la tensión con el Ministro de Hacienda.

26. DuвEт: «La suspensión...».

27. Torrenueva escribía lo siguiente a Sebastián de la Cuadra a 10/08/1737: «si la poderosa mano del rey no las sostiene [sus propuestas de reforma] como se propone a Su Majestad, no se puede pasar adelante». AGS, SSH, leg. 408-1.

28. A 09/08/1739, escribía a Cuadra, entonces marqués de Villarías, que la razón política llamada de Estado debía apoyar a la Hacienda, relatando su conflicto con Montemar. AHN, Estado, libro 827.

29. Dimite a 02/12/1739, reiterando la demanda dos veces, según Vega. «Trata de los gastos», AHN, E, libro 916, fols. 160-163. El rey acepta su «dejación» a 09/01/1740. AHN, E, leg. 6401-1.

30. Cfr. supra, nota 10-20. Juan Bautista de Iturralde recibió el título de marqués de Murillo al abandonar su cargo de Ministro. 
miembro del Consejo de Indias como recompensa a sus anteriores servicios de Ministro, se le confiere ahora una plaza en la Cámara del mismo, realzando su honor. Asimismo, es Secretario de Estado y Superintendente General de Rentas Generales $^{31}$. Sin embargo, aunque se beneficia de las mismas competencias que sus predecesores inmediatos ${ }^{32}$, su posición política es distinta. Lo ilustra la creación de la Junta de Hacienda.

Esta se hace en dos momentos. Al poco tiempo de nombrar a Verdes Montenegro, el rey le invita, por medio de su secretario del Despacho de Estado, Sebastián de la Cuadra, marqués de Villarías ${ }^{33}$, a reunirse regularmente en la Secretaría del Despacho de Hacienda con el Ministro de Guerra Montemar y tres oficiales generales de la Junta del Almirantazgo, en los días que señale Verdes Montenegro (21 de enero). A este corresponde la iniciativa de invitar además al duque de la Mirandola y al cardenal Molina. Verdes Montenegro lo justifica por el enorme atraso de las Casas Reales y caballerizas, de que Mirandola se ocuparía, así como de tribunales y «ministerio», que corresponderían a Molina. Indica que, como no se entrará en el detalle del reglamento de las Casas Reales, no es preciso que entren sus demás jefes ( 24 de enero). El rey avala la propuesta a 25 de enero ${ }^{34}$. La Junta de Hacienda se establece a 16 de febrero con esta composición ${ }^{35}$, añadiéndose al colectivo el duque de Atri, mayordomo mayor de la reina. Los tres oficiales generales de Marina que participan son Francisco Cornejo, el marqués de Mari y Rodrigo de Torres, que forman parte del Consejo del Almirantazgo desde su creación en $1737^{36}$. Posteriormente, se une al grupo el secretario del despacho de Marina e Indias, Joseph de la Quintana ${ }^{37}$. Esta composición no es anodina. Vega tiene razón cuando cree que se busca fortalecer la influencia de Molina. Este, al contrario de lo que hizo en 1737-1739 con la Junta de Medios, participa activa-

31. Cfr. supra, nota 10.-21 Su título indica que también es Secretario de Estado.

32. Con una restricción: Torrenueva no fue Gobernador del Consejo. Dubet: «Entre razón...».

33. Sucedió a Patiño al morir este como Secretario de Estado y de Guerra. En la Secretaría de Guerra, no obstante, delegó gran parte del trabajo a Casimiro de Uztáriz. Zuluaga Cítores, A.: Sebastián de la Quadra, Secretario de Estado en el reinado de Felipe V, primer marqués de Villarias (1687-1766). Santander, 1999. GLESENER: «Reformar».

34. AGS, SSH, leg. 396-2.

35. Verdes Montenegro a Vega, 16/07/1740. AHN, E, libro 827.

36. Andújar Castillo: «La Hacienda», p. 544. Solbes Ferri, S.: «El control del gasto de la Marina española en las Secretarías de Estado y del Despacho. Los pagos dependientes de la Tesorería General en la primera mitad del xviII», en BAUDOT, M. (ed.), El Estado en guerra. Expediciones navales españolas en el siglo XVIII. Madrid, Polifemo, 2014, pp. 147-194.

37. Nombrado al mismo tiempo que Iturralde, recibió la calidad de Secretario de Estado a 12/03/1739. AHN, E, libro 249, fols. 123-124. 
mente. Por otra parte, como nota Andújar Castillo, se confiere un peso destacado a los responsables de Marina y los jefes de las Casas Reales. La diferencia de composición entre la Junta de Hacienda y la de Medios aclara el propósito de los gobernantes a principios de 1740. En 1737, entraron en la de Medios, al lado del Gobernador de Castilla, el Ministro de Hacienda y el de Guerra, unos especialistas del estado de las rentas y de las formas de su control (un Consejero de Hacienda, el Secretario de Millones, el Contador General de Valores y el Superintendente de Juros), como si el Secretario de Hacienda quisiera rodearse de individuos competentes en materia de Hacienda. La Junta de Hacienda, en cambio, es un foro de responsables de los departamentos que gastan más, no de especialistas de la Hacienda. A todas luces, su primer objeto es la negociación entre ellos. Cabe conjeturar que Verdes Montenegro, aleccionado por las dificultades de sus predecesores, buscaría contener a los responsables de Guerra, Marina y Casas Reales obligándolos a conocer el estado de la Hacienda, o que estos presionaron para que se reconociera su participación. En los dos casos, la solución encontrada sin duda reduce la influencia del Ministro de Hacienda en la distribución de caudales, su prerrogativa oficial. Como consecuencia de la creación de la Junta de Hacienda, la de Medios dimite ${ }^{38}$ y su secretario entrega su documentación a la Secretaría de Hacienda ${ }^{39}$.

Las decisiones tomadas en estas condiciones, contrarias a las de Iturralde, se parecen a un arreglo de cuentas. En 1739, Iturralde acabó con el arrendamiento de rentas generales confiado a Juan Evangelista Giraldeli desde $1734^{40}$, instituyendo dos nuevos directores de rentas generales a partir de 1740 para su administración directa $^{41}$. Se anula esta creación a 5 de junio, confiándose la administración al Superintendente de ellas, Verdes Montenegro, lo que restablece la situación anterior a 1734, aclara el decreto ${ }^{42}$. Como consecuencia, Felipe V anula la reforma de la jurisdicción de las rentas generales: se restituye al Consejo de Hacienda la competencia conferida en diciembre a la Junta del Tabaco ${ }^{43}$. La Dirección General

38. Carta de sus miembros, el marqués de Uztáriz, Joseph Ventura Güell, Antonio López Salces y Alejandro de Vega al rey, marzo de 1740. AGS, SSH, leg. 409-2.

39. Verdes Montenegro a Vega, 16/07/1740. AHN, E, libro 827.

40. «Confrontación de el precio que ofrece anualmente don Juan Evangelista Giraldeli con el que rindió a Su Majestad por el quinquenio la última administración de las rentas», anterior a diciembre de 1739. AGS, SSH, leg. 398.

41. Nombró a Antonio de Pando (Bringas) y José de Aguirre Acharán. AHN, FC-MH, libro 8013, núm. 653 y libro 7934, fols. 130-131.

42. AHN, FC-MH, libro 8014, núm. 671 y libro 7934, fol. 167. 172.

43. Felipe V a Verdes Montenegro, Aranjuez, 22/06/1740. AHN, FC-MH, libro 7934, fol. 
del Tabaco desaparece en el mismo movimiento: a los tres directores nombrados por Iturralde (Juan Francisco de Luján, Juan Francisco de Goyeneche y Martín de Loynaz) sucede un solo superintendente, colocado debajo de la autoridad de Verdes Montenegro en su calidad de Superintendente General de las rentas generales. Se nombra a Luján ${ }^{44}$, una señal, tal vez, de desaprobación del trabajo de Loynaz, redactor de la instrucción de la renta publicada en enero ${ }^{45}$. Finalmente, a 22 de septiembre, se anula la reforma de la planta del Consejo de Hacienda adoptada por Iturralde, que reducía las competencias de los letrados ${ }^{46}$. Parece evidente que el nuevo equipo quiere deshacer parte de la política de 1739 y desea que se sepa. En el caso de Iturralde, esta orientación adquiere tintes punitivos. En agosto de 1740 , la Junta, bajo el impulso de Molina, inicia investigaciones sobre los negocios en que la «sagacidad industriosa de los particulares» sacó beneficios ilegítimos de la Hacienda real. Constituye una junta dirigida por el cardenal para juzgar el contrato de cesión de la renta de Población de Granada a Iturralde, otorgado en 1725 , lo que este interpreta como una venganza ${ }^{47}$.

La ruptura más explícita concierne a la suspensión de pagos. A 6 de abril, el rey publica su voluntad de restablecer la fe pública, invitando a los interesados en la suspensión a proponer medios para extinguir sus cartas de pago sin faltar a las obligaciones del Estado ${ }^{48}$. No es una anulación automática de la suspensión: se busca manifestar la buena voluntad del soberano para atenuarla. La decisión se explica a

44. A 05/06/1740. AHN, FC-MH, libro 7934, fol. 167. Hacia 1739, un autor anónimo justificaba la vuelta a un solo responsable de la renta, situado debajo de la autoridad del Ministro, como en tiempos de la Superintendencia de Jacobo de Flon hasta 1726 (González Enciso, A.: «Lenta recuperación y consolidación. La renta a mediados de siglo, 1740-1760», en GonZÁLEZ Enciso, A. (ed.): Política económica y gestión de la renta del tabaco en el siglo XVIII. Los libros de Altadis, 2008, pp. 175-210, pp. 184-185).

45. Escobedo Romero, R.: El tabaco del rey. La organización de un monopolio fiscal durante el Antiguo Régimen. Pamplona, EUNSA, 2007, pp. 75-76.

46. Se les vedó el acceso a las salas de Gobierno y Millones (mayo de 1739). Gallardo FERNÁNDEZ, F.: Origen, progreso y estado de las rentas de la corona de España. Madrid, Imprenta Real, 1805-1808, t. 1, libro 1, pp. 90-93.

47. Consulta de la junta de Hacienda, 22/08/1740. Protesta de Iturralde, 23/09/1740. AGS, SSH, leg. 398-1. Molina a Verdes Montenegro, 24/08/1740. AGS, SSH, leg. 396-2. Caro Baroja: La hora, pp. 229-231, 243; GARzón PAREJA, M.: «La renta de población del reino de Granada», Cuadernos de la Alhambra, 18, 1982, pp. 207-229; CRuz Mundet, J. R.: «Iturralde y Gamio: un asentista navarro en la corte de Felipe V», Príncipe de Viana, 255, 2012, pp. 205-260; Dubet, A.: «Entre servicio del rey y tráfico de efectos: la doble negociación de Juan Bautista de Iturralde», Librosdelacorte.es, $n^{\circ}$ 13, Otoño-invierno 2016. https://revistas.uam.es/librosdelacorte/article/ view/7041/7410. 397.

48. Decreto resumido en la consulta de la junta de Hacienda, 09/09/1740. AGS, SSH, leg. 
posteriori: con el «golpe dado en el corte de suspensión de libranzas», se «falt[ó] a los contratos», «notoria falta de fe» que tuvo «perniciosas consecuencias tanto en los dominios de Vuestra Majestad como fuera de ellos». En particular, en Madrid, donde «estaba recogido casi todo el caudal del reino», los hombres de negocios están "poseídos del temor» ${ }^{49}$. Tal juicio se basa en una justificación de lo que Daniel Dessert llamara el «sistema fisco-financiero ${ }^{50}$. A través de los titulares de las cartas de pago del Tesorero General suspendidas, la medida alcanzó a un sector social de la corte que se suele esconder detrás de testaferros «veinte o treinta sujetos que daban su nombre para la negociación», confiándoles «el caudal grande o pequeño con que se hallaban» y contando con el compromiso del rey de reembolsar. Así,

en los diez millones de escudos que comprehendió el corte fueron inclusos muchos caudales de testamentarías que se hallaban aplicados a diversos fines, mandas a dotes de doncellas huérfanas que, esperando a tener la edad competente para tomar estado, empleaban el dinero a lícito lucro por tiempo determinado, hasta que llegase el caso preciso de valerse de él y darle su aplicación ${ }^{51}$.

En otros términos, la distinción que hizo Iturralde en 1739 entre los honrados ahorristas que prestaban por medio de los Gremios de Madrid y los especuladores no está fundada: los primeros confían su dinero a los hombres de negocios. La Junta concluye, lógicamente, que el interés reconocido a los prestamistas antes de la suspensión por el atraso en reembolsarles se destinaba a los pequeños ahorristas,

dividiéndose aquel beneficio entre todos, de forma que muchas veces el negociante con quien se hallaban era el que tenía la menor utilidad y aun acaecía que ninguna ${ }^{52}$.

Así, aunque «en lo general, la idea principal que rige a los hombres de negocios, asentistas y arrendadores se endereza a enriquecer (sic) con desmedida codicia», algunos solo buscan

socorrer las obligaciones del Estado, entrando y saliendo de su poder los caudales sin llave que los encierre, para que estén al descubierto y sirvan cuando se necesiten. Y el decreto referido a todos midió con una propia vara ${ }^{53}$.

Los verdaderos prestamistas son buenos cristianos que buscan hacer un «lícito lucro» con fines caritativos. Los hombres de negocios que hacen de

49. Consulta de la junta de Hacienda, 12/07/1740. AGS, SSH, leg. 397.

50. Dessert, D.: Argent, pouvoir et société au Grand Siècle. París, Fayard, 1984.

51. Consulta de la Junta de Hacienda, 06/09/1740. AGS, SSH, leg. 397.

52. Idem, nota 51 .

53. Ibidem. 
intermediarios no son avarientos que estancan el dinero escondiéndolo. Suele moverlos la generosidad, para con el rey y para con los prestamistas. De forma paradójica, aunque protegen el secreto de la identidad de los prestamistas, ponen su dinero «al descubierto» facilitando su circulación. Como los más no actúan por codicia, el interés del $8 \%$ que la suspensión anuló era lícito ${ }^{54}$.

La Junta quiere evitar la violencia que ve en la suspensión, porque no permitirá descubrir los caudales escondidos en iglesias. Después de la orden de abril de 1740, busca restaurar la confianza dialogando con los hombres de negocios escaldados. Instalada en el Buen Retiro con el rey, la Junta propone así que los visite Molina, «Ministro tan autorizado y de tanta persuasión» ${ }^{55}$. No se solicita a Verdes Montenegro, quien se queda con la Junta. El detalle ilustra la pérdida de protagonismo del Ministro de Hacienda, que ya no es el interlocutor privilegiado de los hombres de negocios. El procedimiento posterior de Molina confirma la reorientación de la política crediticia de la monarquía. En efecto, solicita a Herce quien, entretanto, se libró de su causa judicial por fraude en la tesorería del tabaco ${ }^{56}$. La Junta elogia al antiguo agente, «persona instruida en el comercio de Madrid $\mathrm{y}$ de gran conocimiento con los hombres de negocios» ${ }^{57}$. Este retorno de Herce significa la vuelta a las anticipaciones respaldadas en rentas futuras. A demanda de la Junta, contacta con arrendadores de rentas provinciales y otros hombres de negocios, aunque tal vez no todos los sugeridos por la Junta ${ }^{58}$. A los arrendadores, se pide una anticipación de seis meses, prorrogando en contrapartida sus arrendamientos para cuatro años más ${ }^{59}$. Herce es invitado a combinar la amenaza de una «sensible resolución» a los que se nieguen, y la invocación del imperativo moral que pesa en los «usufructuarios» de los bienes de la corona ${ }^{60}$. En aquellas

54. Para todo este párrafo: Idem, nota 51.

55. Consulta de la Junta de Hacienda, 12/07/1740. AGS, SSH, leg. 397.

56. Juan Francisco Lobato Ocampo a Verdes Montenegro, julio de 1740. AGS, SSH, leg. 226-2. Rafael Anselmo al mismo, 25/11/1740. AGS, SSH, leg. 227-2.

57. Consulta de la junta de Hacienda, 09/09/1740. AGS, SSH, leg. 397.

58. Esta preparó una relación de los individuos a solicitar, indicando la cantidad que se les podría exigir. Figuraban en primera posición Iturralde y Antonio Pando el Mayor, o sea Pando Bringas, antiguo director de rentas generales. Seguían dos financieros navarros, Juan de Sesma y el marqués de Pontejos, y el marqués de Villanueva (Ventura de Pinedo). «Nota de los sujetos acaudalados que pueden contribuir para la presente urgencia [...]», 12/07/1740. AGS, SSH, leg. 396-2. La lista sin duda refleja la capacidad financiera atribuida a cada uno, pero también la oportunidad de que contribuyan, según criterios no indicados: la poca participación de grandes casas se puede explicar por su implicación en negocios importantes; en el caso de Iturralde, este cree que se pretendió castigarlo (cfr. nota 47-11).

59. Molina a Verdes Montenegro, 24/08/1740. AGS, SSH, leg. 396-2.

60. Consulta de la junta de Hacienda. 06/09/1740. AGS, SSH, leg. 397. 
fechas, Ventura de Pinedo, tesorero de la Cruzada, vuelve a los negocios. En mayo y junio de 1740, presta 200.000 pesos (3 millones de reales) para la expedición de Orán. Para hallar dinero efectivo, hace «vales de la porción que le faltó para que se buscasen en el comercio» - probablemente se vale de la renta de la Cruzada ${ }^{61}$. Por otra parte, en septiembre, la Junta menciona tratos con Giraldeli, privado por Iturralde del arrendamiento de las rentas generales, quien propone volverlas a arrendar ${ }^{62}$. Ahora bien, Giraldeli pide que, a cambio de una elevación del precio del arrendamiento, se anule la suspensión que le afectó en $1739^{63}$. Idéntico trato se acaba de hacer con ciertos arrendadores de salinas. Según la Junta, es una señal de que el rey desea reparar el error de la suspensión ${ }^{64}$. Dos de los beneficiarios de tales acuerdos podrían ser Carlos Brea y Mateo Herroz Ibarra ${ }^{65}$. Otro podría ser Miguel de Arizcun, criticado por Vega en 1738-1739 por sus fraudes en el arrendamiento de las salinas andaluces ${ }^{66}$. Los tres fueron alcanzados por la suspensión de 1739 - para Brea y Arizcun, en sumas elevadas ${ }^{67}$. Poco después, el rey manda prorrogar los arrendamientos de rentas provinciales, con tal que los recaudadores paguen en seguida 6 mesadas de anticipación, invitando a Verdes Montenegro a arrendar la del tabaco, si un candidato acepta pagar una anticipación ${ }^{68}$.

La política diseñada aquí es una decidida vuelta al crédito, que busca alterar los equilibrios entre las casas de negocios más influyentes en Madrid. Así, los acuerdos iniciados con individuos a los que Iturralde quiso castigar, además de presentarse como una reparación, se pueden interpretar como una forma de restaurar la influencia de grupos de negocios ajenos a la red del ministro caído. Lo confirma la destitución de Juan Francisco de Goyeneche, sobrino de Juan, el

61. El conde de Villanueva, Antonio de Pando, Juan de Sesma, Antonio de Pando y Sabugal, Joseph Negrete, Juan Bautista Bonavia, Alberto Gómez de Andrade a Miguel Lorenzo Masero (secretario de la junta), 07/08/1740. Resumida en la consulta de 06/09/1740. AGS, SSH, leg. 397.

62. Dio un pliego en junio o antes. Verdes Montenegro a Villarías, Aranjuez, 29/06/1740. Consulta de la junta de Hacienda, 06/09/1740. AGS, SSH, leg. 397.

63. Idem, nota 62. Verdes Montenegro a Villarías, 29/06/1740. AGS, SSH, leg. 397.

64. Consulta de la junta de Hacienda, 06/09/1740. AGS, SSH, leg. 397.

65. Según la base Fichoz. Dedieu, J. P.: «Fichoz 2011. Balance de una base de datos sobre la España moderna», en Jiménez Estrella, A., Lozano Navarro, J., Sánchez Montes, F. y Birriel Salcedo, M. (eds.): Construyendo historia. Estudios en torno a Juan Luis Castellano, Editorial de la Universidad de Granada, 2013, pp. 185-200.

66. «28 reflexiones sobre hacienda y su administración», s.f., AHN, E, libro 789. Arizcun ya arrendó estas salinas en los años 1720. José Patiño a Juan de Valdés y Nasao, 18/12/1728, AHN, SSH, leg. 212-2.

67. Dubet: «La suspensión...».

68. Felipe V a Verdes Montenegro, San Ildefonso, 28/09/1740. AHN, E, libro 793. 
difunto amigo de Iturralde ${ }^{69}$. No es una política hostil al conjunto de los navarros, que no necesariamente forman un frente común ${ }^{70}$. Así, algunos de ellos se benefician de las disposiciones de Molina. Herroz es congregante de San Fermín ${ }^{71}$. Arizcun, uno de los financieros navarros más influyentes, arrienda la renta de lanas y provee los víveres de Marina ${ }^{72}$; se beneficia del apoyo de Molina, como veremos. Parte de los arrendadores de rentas provinciales están relacionados con Iturralde y los herederos de Goyeneche ${ }^{73}$. La Junta, Molina y tal vez Verdes Montenegro podrían aspirar más bien, a reducir la prepotencia de la que gozan Goyeneche y sus socios desde la Guerra de Sucesión. Como consecuencia, el crédito de la Tesorería General debería basarse en el soporte de grupos más diversos que en los años 1720.

Por otra parte, la Junta estima que el mejor remedio es empeñar las rentas del año sucesivo para satisfacer las urgencias presentes y admite que este crédito tiene un precio. Este no se describe como la remuneración de la usura, sino como el rédito de las inversiones cristianas de los pequeños ahorristas y el pago del trabajo de los hombres de negocios que dan la cara por ellos, además de la obligación del rey de remunerar a súbditos que se sacrifican para servir. Por supuesto, no se menciona ninguna posibilidad de tráfico de efectos de la Tesorería Mayor de parte de Herce, aunque cuesta imaginar que este renuncie a sus recetas usuales se le eligió precisamente por su experiencia en negocios discretos. Aun así, no conviene exagerar la oposición entre la política de la Junta y la de Iturralde. Creo

69. Aquerreta, S.: Negocios y finanzas en el siglo XviII: la familia Goyeneche, Pamplona, EUNSA, 2001.

70. El vínculo entre paisanos o parientes no determina una solidaridad automática. GUERRERO Elecalde, R. e Imízcoz Beunza, J. M.: «Familias en la monarquía. La política familiar de las élites vascas y navarras en el Imperio de los Borbones», en Imízcoz Beunza, J. M. (ed.): Casa, familia y sociedad (País Vasco, España y América, siglos XV-XIX). Bilbao, Universidad del País Vasco, 2004, pp. 177-238. Torres SÁnchez, R. (ed.): Volver a la "hora navarra». La contribución navarra a la construcción de la monarquía española en el siglo XVIII, Pamplona, EUNSA, 2010.

71. Fichoz.

72. TORRES SÁNCHEZ, R.: «Los navarros en la provisión de víveres a la Armada española durante el siglo xviII», en Torres SÁnchez, R. (ed.): Volver..., pp. 213-262. González Enciso, A.: «Empresarios navarros en la industria de municiones para la artillería», en TORREs SÁNCHEZ, R. (ed.): Volver..., pp. 158-211. Cfr. nota 73. Sobre la renta de lanas: Campillo a Villarías, Zaragoza, 14/01/1741. AHN, E, leg. 3149.

73. Aquerreta: Negocios...; González Enciso, A. (ed.): Navarros en la Monarquía española en el siglo XVIII. Pamplona, EUNSA, 2007; Dedieu, J. P.: «Les groupes financiers et industriels au service du roi - Espagne. Fin Xvire - début XviIIe siècle», en DubET, A. y Luis, J. P. (eds.): Les financiers et la construction de l'Etat en France et en Espagne (milieu du XVIIe siècle-milieu du XIXe siècle). Rennes, PUR, cap. 5.

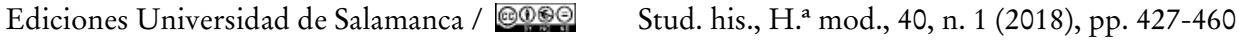


que el cambio de 1740 no obedece tanto a una visión teórica y moral del crédito como a la estrategia. La Junta no pretende restablecer de forma indiscriminada todos los créditos cortados, sino negociarlos con los titulares, dinero mediante, restableciendo de forma prioritaria el diálogo con los mayores actores de las «negociaciones» de 1734-1738. Las dificultades encontradas obligan a precisar cómo la Junta concibe el trato con los hombres de negocios. Así, los individuos solicitados por Herce empiezan negándose, mencionando el daño que les causó la suspensión ${ }^{74}$. La otra dificultad reside en el recurso a un intermediario. Primero, porque la discreción del trato hace que nadie se quiera comprometer por escrito. Segundo, la autonomía del intermediario es problemática: Herce va demasiado lejos, ofreciendo a los que presten dinero el restablecimiento de sus «cartas de negocios cortadas». A 6 de septiembre, la Junta reconoce que es imposible, porque se suspendieron 10 millones de escudos de libramientos cuando las rentas totales del año montan 21 millones ${ }^{75}$.

\section{El Secretario de Hacienda, ¿Ministro o subordinado de sus colegas?}

Las dificultades encontradas llevan a cuestionar las facultades del Ministro de Hacienda y la mecánica de la Tesorería colocada debajo de su autoridad. En efecto, la Junta trabaja bajo la presión de las sorpresas de la guerra. Así, decidió inicialmente reducir todos los gastos en un tercio: basándose en los estados de fondos y cargas del año establecidos en tiempos de Iturralde ${ }^{76}$, aplicaba esta tasa porque el fondo cubría las dos terceras partes de las cargas. Esta decisión es invalidada en marzo de 1740, cuando la expedición naval de Mahón, la salida de la flota de Galicia y el repuesto de Orán causan gastos imprevistos. Se pone entonces en obra la venalidad sistemática de oficios y honores en las Indias ${ }^{77}$. La medida, aplicada bajo la dirección de Molina, parece consensual en la Junta ${ }^{78}$. Para aplicarla, se crea una tesorería ejercida por Miguel de Arizcun en toda confianza es «relevado de fianza». Como las cajas de rentas, distribuirá los caudales según órdenes comunicadas por vía de

74. Pinedo, Pando Bringas, Sesma, Pando y Sabugal, Negrete, Bonavia, Gómez de Andrade a Masero, 07/08/1740. Resumida en la consulta de 06/09/1740. AGS, SSH, leg. 397.

75. Consulta de 06/09/1740. AGS, SSH, leg. 397.

76. En noviembre de 1739 (AGS, SSH, leg. 398-2). Se les añaden balances de deudas en enero (AGS, SSH, leg. 396-2) y evaluaciones de los fondos desempeñados por la suspensión (AGS, SSH, leg. 396-1).

77. «Medios discurridos y de que se ha tratado en la junta desde enero de 1740 que se estableció para ocurrir a las cargas de la corona» (1741). AGS, SSH, leg. 398-2.

78. Burgos Lejonagoitia, G.: Gobernar las Indias. Venalidad y méritos en la provisión de cargos americanos, 1701-1746. Almería, Universidad de Almería, 2015, pp. 246-256. 
Verdes Montenegro y cartas de pago del Tesorero Mayor, situándose así bajo el control de la Tesorería General ${ }^{79}$. La creación de esta nueva caja podría ser uno de los motivos de la inquina del anónimo citado por Caro Baroja.

La venalidad podría ser el único punto de acuerdo de la Junta de Hacienda. En efecto, su historia es la de sus conflictos. Uno de ellos concierne a la política fiscal y opone a la Junta de Hacienda con una junta de teólogos. Otro, el más vivo, opone al Ministro de Hacienda y los responsables de los departamentos que gastan más - primero, el Ministro de Guerra y, en fin de año, los responsables del Almirantazgo. Este enfrentamiento les lleva a intentar redefinir sus competencias respectivas, con proposiciones inconciliables. En un segundo momento, se pone en tela de juicio la unidad de «bolsa» de la Tesorería Mayor. En los dos conflictos, se enfrentan Verdes Montenegro y Montemar.

El conflicto fiscal surge en junio, al reunirse una junta de teólogos en casa de Molina. A 17 de junio, Verdes Montenegro le expone la situación del erario, pormenorizando los fondos disponibles y deudas vigentes. Como resultado, «hecho el más arreglado presupuesto», se necesita buscar 4 millones de pesos (60 millones de reales). La Junta examina entonces los medios propuestos por Molina y Verdes Montenegro. De estos medios, cuya lista no se da en la consulta, extrae la siguiente propuesta: un alza del derecho sobre la sal, que no compensaría la reducción operada por Luis I en 1724; durante un año, un valimiento de la mitad del producto de sisas y arbitrios municipales, en las dos coronas de Castilla y Aragón, cuyo único inconveniente sería retrasar el pago a los acreedores de los municipios; un alza de las rentas provinciales en el 15\%; unos 4 puntos más en la percepción de la alcabala en Madrid, recaudada por los Gremios Mayores; en la corona de Aragón, durante un año, un donativo de 1 peso por vecino, que compensaría la desigualdad de la carga fiscal entre las dos coronas; el restablecimiento del valimiento de las hierbas anulado por Luis I. La ventaja de estos medios es que su recaudación no requiere crear nuevas administraciones. La Junta justifica esta nueva fiscalidad por la clásica doctrina fiscal. Dándose la guerra contra Gran Bretaña, moviliza el argumento religioso. Además, la nueva fiscalidad cesará con la necesidad la guerra, por estar el rey obligado en conciencia a ello. Por otra parte, la Junta pretende que los habitantes de Indias contribuyan más, "por ser aquellos vasallos quienes principalmente reciben el beneficio de esta defensa». Ya que la moral prohíbe exigir más de la necesidad, se calcula el producto esperado de cada medio, llegando a un total de 3,9 millones de pesos ${ }^{80}$. La consulta de la

79. Verdes Montenegro a Nicolás de Aristizábal, Aranjuez, 03/05/1740. AHN, FC-MH, libro 7934, fols. 161-162.

80. AGS, SSH, leg. 397. 
Junta de Teólogos no indica cuál fue la posición defendida por cada miembro. Nos enteramos a posteriori de que ni Verdes Montenegro ni la Junta de Hacienda asumen la propuesta. A 23 de junio, esta indica al rey que conviene evitar gravar a los súbditos. Es posible hacerlo recurriendo al «producto de los beneficios», o sea la venalidad indiana, y al crédito. La Junta cuenta en aquel entonces con un préstamo de un millón de pesos que el rey pidió al Consulado de Cádiz y ya se propone solicitar a los recaudadores de rentas provinciales. Sin embargo, se reserva la posibilidad de volver a considerar estos medios dentro de tres meses, por si resultaran insuficientes ${ }^{81}$. Esta línea conduce a la Junta a entrar en tratos con Herce. Como el rey anuncia entonces que el millón de Cádiz se reserva a otro empleo (no precisado), se podría pedir hasta 4,72 millones de pesos a los arrendadores ${ }^{82}$.

El debate fiscal agrava la tensión entre Verdes Montenegro y Montemar. El Ministro de Guerra es incansable. Multiplica las cartas a Villarías y Verdes Montenegro, añadiendo papeles transmitidos por mano del responsable efectivo de la Secretaría de Guerra, Casimiro de Uztáriz. Reitera sus razones de una carta a otra: los fondos dados a las tropas son insuficientes, no llega a las tesorerías de guerra lo prometido por Verdes Montenegro o llega con retraso. El propio Montemar ofrece una estadística de su actividad. A 16 de agosto, representa a Villarías que desde el 18 de marzo redactó 27 representaciones ${ }^{83}$. Esta rica correspondencia permite estudiar las formas de financiación de la guerra ${ }^{84}$. Nos informa también sobre el conflicto político en torno a la distribución de caudales. Parece empezar en febrero de 1740, cuando Montemar exige que los intendentes de ejércitos no distribuyan fondos sin que él lo sepa, reclamando una orden de Verdes Montenegro para ello ${ }^{85}$. Durante este mes, Verdes Montenegro recibe solicitudes cotidianas para la expedición de Mahón. Contesta explicando sus disposiciones ${ }^{86}$, pero también hace una respuesta política. A 4 de marzo, en una larga carta a Villarías, interpreta la actitud de Montemar como una usurpación de sus propias competencias:

lo que prueba el papel del Duque es buscar con tan débiles motivos la distribución de la Hacienda y sofocar al Ministro encargado de ella, y no será dable subsistir ni hacer el servicio del rey en semejante sixtema (sic) ${ }^{87}$.

81. Consulta de la junta de Hacienda, 23/06/1740. AHN, SSH, leg. 397.

82. «Nota de los sujetos acaudalados», AGS, SSH, leg. 396-2.

83. Montemar a Villarías, San Ildefonso, 16/08/1740. AGS, SSH, leg. 398-1.

84. La explota Andújar CastillO: «La Hacienda...».

85. Montemar a Verdes Montenegro, Madrid, 18/02/1740. AGS, SSH, leg. 399-1.

86. AGS, SSH, leg. 396-2.

87. Dos cartas de Verdes Montenegro a Villarías, Madrid, 04/03/1740. AGS, SSH, leg. 396-2. 
En particular, Montemar «se propasa a decir» que Verdes Montenegro obstaculiza la provisión de Mallorca y Galicia. Montemar también lo acusa de hacer contratas de paños y vestuario sin saber de qué se trata. Verdes Montenegro contesta que siempre fue así en tiempos de Campoflorido, refiriéndose así a la época en que el Secretario se impuso como el único canal de la negociación con la gente de negocios; además, él consultó a Montemar antes de elegir al asentista. «Pero nada le satisface mientras no se le encargue la distribución general de la Hacienda». A su vez, Verdes Montenegro acusa: Montemar tiene dos discursos distintos, según se encuentre en la Junta -donde es más conciliador-o fuera de ella. La solución, para Verdes Montenegro, es también política, y es un esbozo de lo que propondrá meses después. Pide que la Junta «informe y tenga el conocimiento en lo general de la distribución», lo que convendrá a Montemar «por ser Ministro de ella». En otra carta, precisa que se trata de que la Junta, «examinado lo urgente y lo que no lo sea tanto, distinguiese los pagamentos y (sic) informase a Vuestra Majestad con su dictamen ${ }^{88}$. Sin duda es una tentativa para neutralizar a Montemar sin ofenderlo. Verdes Montenegro no está dispuesto, en aquel momento, a renunciar a sus principales facultades de Ministro. Como contrapartida a su concesión, el primer oficial del Despacho de Guerra, Uztáriz, debería mostrar a Verdes Montenegro las informaciones reclamadas por este. El rey acepta. A 10 de marzo, confiere a la Junta el «conocimiento en lo general de las distribuciones del erario para atender a las clases respectivas, según lo pidan las ocurrencias» ${ }^{89}$.

La estrategia de Verdes Montenegro fracasa. La consulta de los teólogos provoca otro enfrentamiento. Según Montemar, hostil a los medios fiscales propuestos, se recurre a ellos por «la falta de dirección en la Hacienda, y no la necesidad». En otros términos, por la incapacidad política de Verdes Montenegro y/o de la Junta. Considera que hay soluciones más eficientes y menos dañosas para los contribuyentes, como el arrendamiento de las rentas generales y el de la renta del tabaco por partidos, el abandono de la administración directa de la provisión de víveres y del vestuario y la prorrogación de las rentas provinciales. Se podrá confiar el gasto del millón del Consulado de Cádiz a Verdes Montenegro y se seguirá con la venalidad indiana. Todo puede funcionar si se tranquiliza a los hombres de negocios restableciendo «la buena fe en los tratos». En el caso de las rentas generales, utiliza unos argumentos que ya se opusieron a Iturralde en 1739:

88. Dos cartas de Verdes Montenegro a Villarías, Madrid, 04/03/1740. AGS, SSH, leg. 396-2.

89. Consulta de la junta de Hacienda, 04/01/1741. AHN, E, leg. 3149. Uztáriz es Secretario interino de 1735 a octubre de 1741. Villarías, titular, conserva el despacho con los reyes (Fichoz). 
los defensores de la administración directa solo quieren proteger sus fraudes ${ }^{90}$. Como consecuencia, se niega a rubricar la consulta de la Junta de Hacienda de 17 de junio y aunque firma la del 23, añade su voto particular ${ }^{91}$. Verdes Montenegro responde atacando. Denuncia la poca fiabilidad del Ministro de Guerra, quien no aplica los compromisos que asume en la Junta, y su mala fe, ya que no reconoce haber recibido todos los fondos aplicados a Guerra (casi 14 millones en lugar de los 10 de la previsión inicial). Critica su propuesta fiscal, infundada: la oferta de Giraldeli para las rentas generales es insuficiente, ya que los valores de la renta administrada en 1740 han crecido a pesar de la guerra; en cuanto al tabaco, proponer un arrendamiento es carecer de "práctica», ya que nadie podrá arrendar toda la renta y los arrendamientos por partidos son fuente de fraudes. Pero el mayor problema es el ataque a sus competencias de Ministro de Hacienda. Toda oferta de arrendador, explica,

debe tener expedición por su Ministerio y el Consejo y oficinas de Hacienda, causándole admiración los empeños que se hacen sobre que se admita el de Giraldeli, siendo agentes suyos personas de la mayor graduación ${ }^{92}$.

Por otra parte, la correspondencia de Montemar con los intendentes causa confusión, alterando los «presupuestos» - el Secretario de Hacienda reivindica así su propia autoridad sobre ellos ${ }^{93}$. En agosto, Verdes Montenegro se defiende enfatizando su dominio de las cifras y las dificultades a que está confrontado por haber tenido que asumir la situación legada por sus predecesores, además de la guerra. Así, las expediciones marítimas acabaron con el proyecto de reducir los gastos en un tercio, amenazando en particular el pago del prest, ya retrasado en 1737-1738. Los 10,6 millones de reales destinados por la Junta de Hacienda a Guerra en febrero ya están consumidos. La previsión, de todas formas, era insuficiente, ya que solo el prest, los hospitales y provisiones importan 10 millones al año. Así, su talento no entra en consideración. Ahora hacen falta 6,5 millones más para Guerra y casi 3 más para los otros departamentos. Verdes Montenegro dice estar cansado de tener que demostrar constantemente cómo y cuándo distribuye los fondos, con pruebas documentales dadas por la Tesorería Mayor. Considera que le incumbe la organización de la distribución, «por el cargo en que estoy constituido», y su colega le ataca en esta calidad ${ }^{94}$.

90. Representación de Montemar, 21/06/1740. AGS, SSH, leg. 397.

91. Montemar a Verdes Montenegro, Aranjuez, 27/06/1740. AGS, SSH, leg. 397.

92. Memorial de Verdes Montenegro, 29/06/1740. AGS, SSH, leg. 397.

93. Idem, nota 92. Memorial de Verdes Montenegro, 29/06/1740. AGS, SSH, leg. 397.

94. Verdes Montenegro a Villarías, San Ildefonso, 08/08/1740. AGS, SSH, leg. 398-1. 
A partir de entonces, el conflicto deriva en lucha abierta. La representación de Montemar de 16 de agosto de 1740 es asesina. Denuncia el estado deplorable de las tropas, los oficiales, las fábricas de artillería y munición, los hospitales. Las fortificaciones están arruinadas y los asientos, en suspenso, los soldados desertan, los oficiales recurren a medios indecentes para mantener su tropa. Y acusa: más de 150 resoluciones del rey no tuvieron efecto, las dotaciones reducidas en un tercio no se pagaron, salvo para el prest. En fin,

hasta ahora, no se ha logrado otro fruto de las reconvenciones hechas al Ministro de Hacienda y las repetidas órdenes que se le han dirigido del rey por esta vía ${ }^{95}$.

La frase revela que el de Guerra considera al Secretario de Hacienda como un subordinado al que le puede transmitir órdenes. Para justificar su posición, adjunta copias de cinco representaciones previas. La tensión crece en los meses sucesivos porque el texto circula en las provincias, con toda probabilidad por obra de Montemar y sus criados. El rey manda realizar una averiguación ${ }^{96}$ y, en noviembre, Verdes Montenegro se entera de que se distribuyó en Cataluña y Mallorca a los intendentes, al capitán general y a oficiales «de distinción» ${ }^{97}$.

Verdes Montenegro parece contar con el respaldo de la Junta de Hacienda en la defensa de sus competencias, aunque esta no defiende toda su política. Así, a 6 de septiembre, la Junta aprueba el arrendamiento de rentas generales. El debate sobre esta renta continúa después ${ }^{98}$. Podría pasar lo mismo con la renta del tabaco. No obstante, la Junta apoya a Verdes Montenegro en su intento por imponer al Ministro de Guerra un control sobre el detalle de su distribución. Como respuesta, en las reuniones más conflictivas, Montemar vota por disciplina, añadiendo después un voto particular contrario. A fines de 1740, Montemar recibe un poderoso respaldo, ya que los Tenientes Generales de Marina y los Mayordomos Mayores de Casas Reales hacen lo propio. A 6 de septiembre, la Junta propone observar «el más económico repartimiento», incumbiendo a cada uno de sus miembros velar por él en su departamento. El día 20, examinando los documentos contables presentados por Montemar y los jefes de las Casas Reales, decide someterlos al juicio de los Contadores Generales de Valores y Distribución o a los ministros del Tesorero Mayor, manifestando así su recelo. Verdes Montenegro cuenta en efecto

95. Montemar a Villarías, San Ildefonso, 16/08/1740. AGS, SSH, leg. 398-1.

96. En septiembre. Andújar Castillo: «La Hacienda...».

97. Antonio de Horbegozo y Landaeta a Verdes Montenegro, Palma, 19/11/1740. AGS, SSH, leg. 398-1.

98. A 29/10/1740, el contador Salvador de Querejazu critica el proyecto de arrendamiento. AGS, SSH, leg. 398-2. 
con el Tesorero para contestar los reparos de sus colegas 99 . A 29 de septiembre, el rey invita a la Junta, en respuesta a la consulta del 6, a preparar reglamentos para el gasto ${ }^{100}$. La medida se puede interpretar como una forma de obligar a Montemar y los Mayordomos Mayores a solicitar el acuerdo de la Junta para el detalle de sus gastos, estrechando el control sobre ellos en efecto, las facultades iniciales de la Junta solo preveían un examen global del reparto de las cuantías entre departamentos. Como Montemar - y tal vez Mirandola y Atri - no admite aquí el control de Verdes Montenegro, el Ministro de Hacienda busca el respaldo de la Junta y obtiene el apoyo del rey en esta estrategia.

La solución adoptada obliga a todos a asistir a la Junta. Al día siguiente, dada la enfermedad de Montemar, se invita a Casimiro de Uztáriz, secretario interino de Guerra, a entrar en ella ${ }^{101}$. ¿Será una táctica para apartar al Ministro de Guerra? Por otra parte, Verdes Montenegro se apoya en la Junta para solicitar, a 23 de octubre, la disposición de los fondos de la Depositaría de Indias. Aunque esta no forma parte de la red de Tesorería General ${ }^{102}$, la Junta explica que, hasta el nombramiento de Quintana como Secretario de Indias (en marzo de 1739), estuvo debajo de la autoridad del Secretario de Hacienda - dándose órdenes de pagos al Depositario por su vía reservada. No se duda de la integridad de Quintana, pero, según la Junta, el Ministro de Hacienda debería tener «una universal noticia de todo el caudal y efectos de la Real Hacienda y de los parajes y bolsas en que existen para que pueda acudir a lo más urgente». Reclama incluso más: ya que todas las cargas de la Monarquía se pagan

por la Tesorería General o con forzosa dependencia de ella, para que íntegramente conste del fondo y su distribución, es reparable que lo correspondiente a la Depositaría de Indias esté separado de aquel cuerpo, que debe comprender las partes de que se compone el todo ${ }^{103}$.

De momento, el Secretario de Marina debería dar órdenes para poner los fondos de la Depositaría a disposición del actual Ministro de Hacienda y sus sucesores. Los gastos de los manejos de Quintana (Marina e Indias) se harán con órdenes comunicadas por el de Hacienda. Esta demanda forma parte de un plan de coordinación de todo el gasto de guerra: «por la misma causa de que en la

99. Cartas de Miguel Lorenzo Masero a Verdes Montenegro, y de este a Prado Güemes, San Ildefonso, 21/09/1740. AGS, SSH, leg. 398-1.

100. Felipe V a la junta, 29/09/1740. AGS, SSH, leg. 397.

101. Consulta de la junta de Hacienda, 30/09/1740. AGS, SSH, leg. 398-1.

102. Solbes Ferri: «El control...».

103. Resumen de la consulta de la junta de Hacienda, 23/10/1740. AGS, SSH, leg. 396-1. 
guerra se lleve la mejor y más acorde armonía y que conste de todo en la Tesorería General». La Junta aprovecha finalmente la oportunidad para pedir información sobre el millón prestado por el Consulado de Cádiz, que debería ingresar en la Depositaría y gastarse con estas reglas ${ }^{104}$.

El cambio promovido por la Junta para el gobierno de la Hacienda en aquellos primeros meses no corresponde a lo que se podría esperar de un órgano colegial, susceptible de querer cortar las alas al Ministro. Para la Junta, como para Verdes Montenegro, conviene preservar la unidad de decisión del gasto de la monarquía, tanto el que ya se hace en la Tesorería General o en nombre de ella (Guerra y Casas Reales) como el de Marina que se hace en la Depositaría de Indias. El instrumento de esta centralización sigue siendo el Secretario de Hacienda. Además de dar órdenes de pago al Tesorero (algo que no se cuestiona a estas alturas), debería poder darlos al Depositario de Indias. La Junta no parece aspirar de momento a ejercer esta facultad en su lugar. Verdes Montenegro añade a las competencias del Secretario la exclusiva del control sobre la actividad de los intendentes, indispensable para que se ejecute el gasto tal como se prevé en Madrid ${ }^{105}$. Por otra parte, la lista de sus facultades de Superintendente General (iguales a las de sus predecesores y ampliadas en el caso de las rentas generales) y su calidad de Secretario de Estado y del Despacho le equiparan a sus predecesores, desde Patiño. Con todo, la Junta es ambivalente. Frente a la oposición del Ministro de Guerra y los jefes de las Casas Reales, se describe como el foro en el que se negociará el reparto de las asignaciones entre los diversos departamentos antes de que el Secretario emita las órdenes de pago, para mantener en pie la ficción de la subordinación de los demás Secretarios (en particular el de Guerra) al de Hacienda. Asimismo, las iniciativas de Molina en la gestión de la deuda reducen el margen de maniobra de Verdes Montenegro. El Ministro de Hacienda ha perdido poder político y la propuesta de la Junta es a la vez una forma de reconocerlo y de limitar las consecuencias de esta degradación de su posición frente a sus colegas. Cabe suponer que el equilibrio buscado solo será sostenible mientras Verdes Montenegro y el Presidente de la Junta vivan en buena inteligencia. No obstante, la presión de los demás responsables lleva pronto a un cuestionamiento más radical del modelo defendido por el de Hacienda.

104. Resumen de la consulta de la junta de Hacienda, 23/10/1740. AGS, SSH, leg. 396-1.

105. Torres SÁNchez, R.: «La militarisation des finances royales d'Espagne au XviIIe siècle», en Dubet, A. y Luis, J. P. (eds.): Les financiers et la construction de l'Etat en France et en Espagne (milieu du XVIIe siècle-milieu du XIXe siècle). Rennes, PUR, 2011, cap. 9, pp. 177-198. 


\section{LA Disyuntiva: gobierno COLEgial o Desaparición de la Tesorería GENERAL}

El apoyo que los responsables de Marina aportan a Montemar y los jefes de las Casas Reales es decisivo. Ocupa el primer plano Cenón de Somodevilla, marqués de La Ensenada, Secretario del real Almirantazgo. Detrás de él, está el Infante Felipe, Almirante General desde enero de 1740, lo que explica la timidez de la réplica de Verdes Montenegro ${ }^{106}$. Los Tenientes Generales de Marina Cornejo y Mari actúan en consonancia con Somodevilla. Esta participación de los de Marina en la batalla podría explicarse por el peso creciente, en los gastos totales de Marina, del dinero aportado mediante la Tesorería Mayor, desde las expediciones italianas, que fue reduciendo la autonomía de este departamento ${ }^{107}$. Ahora bien, en octubre de 1740, tanto Marina como Guerra obtienen consignaciones aparte. Según una representación posterior de Somodevilla, a 29 de octubre, el rey da órdenes para que

se entregasen luego luego (sic) a disposición del Almirantazgo en efectos de la mayor seguridad a su satisfación (sic) pertenecientes al año de 1741 las consignaciones de 3.333.000 escudos correspondientes a dos terceras partes de su dotación ordinaria ${ }^{108}$.

La cantidad se da «en cartas de pago sobre rentas provinciales, salinas, aguardientes y lanas». Al mismo tiempo, a 24 de noviembre, el rey destina 6 millones a un ejército «de prevención», invitando a Montemar a someter al Tesorero General la lista de las rentas desembarazadas en que quiere que se consigne y precisando que, si las rentas ya están aplicadas a otros fines, se le darán otras cartas de pago sobre otros efectos o sobre el fruto de las anticipaciones de los nuevos arrendamientos de rentas provinciales ${ }^{109}$. El objetivo es que estos departamentos tengan su cantidad anual desde principios del año 1741, en lugar de recibirla mes tras mes. Somodevilla aclara después que disponer de este caudal de una sola vez permite tranquilizar a los prestamistas y, para Marina, el primer cuadrimestre del año es cuando se hacen los mayores gastos ${ }^{110}$. Una queja posterior de Verdes Montenegro revela que Marina dispone también del millón de pesos del Consulado, lo que

106. Solbes Ferri: «El control...». El Secretario de Indias, Quintana, no aparece en el conflicto que referimos.

107. Ibidem.

108. Representación de Somodevilla, 24/12/1740. AHN, E, leg. 3149.

109. Explicación dada en la consulta de la junta de Hacienda, que resume las representaciones de Somodevilla y de Montemar, fechadas a 24/12/1740. Madrid, 04/01/1741. AHN, E, leg. 3149.

110. Somodevilla a Villarías, Buen Retiro, 01/02/1741. AHN, E, leg. 3149. 
explica el malestar de la Junta cuando se enteró, en junio, de que no podía disponer de él. Asimismo, se le destinó un servicio de la compañía de Guipúzcoa ${ }^{111}$.

Esta creación de consignaciones separadas es interpretada en seguida como una ruptura con lo construido desde 1713 con la Tesorería Mayor. Divide a la Junta de Hacienda en dos, llevando a cada grupo a radicalizar su posición. A 19 de diciembre, cuando está elaborando los estados de fondos y cargas de 1741, el Tesorero Joseph de Prado Güemes, sustituto de Moriana ${ }^{112}$, denuncia esta forma de consignaciones entre líneas. Lamenta su poco margen de maniobra. En efecto, la mayor parte de los fondos desembarazados de 1741 ya tienen destino: el caudal de la Cruzada sirve para presidios y galeras -siguiendo las cláusulas de la concesión pontifical-; las contribuciones aragonesas «no tienen más uso que el de consumirse en los mismos reinos en el gasto de la Guerra». El resultado es el profundo «abandono en que queda todo lo que depende de la caja de la Tesorería Mayor, que se reduce a prest del resto de las tropas que sirven en Madrid, y en las provincias, sus víveres y demás obligaciones de Guerra», con algunas reservas. Esta situación contradice el propósito de la creación de la Tesorería:

se ha manejado siempre unido el fondo por una dirección económica y $[\ldots]$ se ha conocido que, de otra suerte y no estando refundido el fondo bajo de una mano, era imposible haber sobstenido (sic) las obligaciones precisas y disimuládose la falta de las que permiten esperar ${ }^{113}$.

De paso, Prado Güemes confirma así que una de las virtudes de la unidad del manejo en un solo Tesorero es facilitar el control de la deuda corriente. Ahora bien, «las últimas reales órdenes» cambiaron la situación. La Tesorería queda «sin facultad alguna [...] para el giro de caudales ni ocurrir dentro y fuera de la corte a urgencia alguna, pues queda en sustancia como cerrada y sin poder contestar a pagamento alguno»114. A pesar de la prudencia de Prado Güemes, se adivina que no se refiere al destino específico de la Cruzada, que no es una novedad, sino a las órdenes de noviembre. Con el apoyo de Verdes Montenegro y de la Junta de Hacienda, se resiste a aplicarlas.

A 24 de diciembre, Montemar y Somodevilla escriben sendas cartas para levantar obstáculos, coincidencia que revela una acción concertada. Somodevilla

111. Verdes a Villarías, Madrid, 26/01/1741. AHN, E, libro 3149.

112. Moriana murió a 31/07/1739 (Fichoz). Felipe V nombró a Prado Güemes como sustituto a 04/08/1739. AHN, FC-MH, libro 7934, fol. 18.

113. Prado Güemes a Verdes Montenegro, Madrid, 19/12/1740. AGS, SSH, leg. 399-1.

114. Idem, nota 113. Prado Güemes a Verdes Montenegro, Madrid, 19/12/1740. AGS, SSH, leg. 399-1. 
reclama órdenes para que «se noten» sus cartas de pago en las Contadurías Generales de Valores, Distribuciones y Millones, «con la prevención de que [...] no se admitan otros efectos con ningún título ni pretexto». Montemar quiere que el director de la renta del tabaco y los arrendadores de rentas provinciales sepan que su consignación es prioritaria ${ }^{115}$. Se trata de cortocircuitar a la Tesorería Mayor y al Secretario de Hacienda, de dos modos. Somodevilla se dirige a las Contadurías Generales, responsables de justificar los gastos realizados por el Tesorero para que, en su posterior rendición de cuentas, se le abonen. Quiere amenazar al Tesorero con no hacerle buenos los pagos que no correspondan a la voluntad del Almirante. Montemar se dirige a los administradores y arrendadores que hacen pagos en nombre del Tesorero General. La Junta de Hacienda responde solicitando la facultad de presentar al rey, cada mes, las obligaciones más «ejecutivas» del siguiente mes, informándole para ayudarlo en su decisión ${ }^{116}$. A 4 de enero de 1741 precisa su demanda, basándola en el comentario de Prado Güemes, apoyado por Verdes Montenegro: la Junta tendría -en la continuidad del decreto de 10 de marzo- el

conocimiento y noticia universal de toda especie de caudales que por cualquier título, motivo o razón pertenezcan a la real Hacienda, ya sea de los de estos reinos y dominios u de los de la América, tanto los que entraren en poder del Depositario de Indias establecido en Cádiz como otros y los que cause la Compañía Guipuzcoana $[\ldots]$, sin separación de alguno que como va referido pueda tocar al real erario ${ }^{117}$.

Cada mes, la Junta compararía la relación del caudal disponible y la de las cargas para proponer la «particular aplicación que se haya de dar al fondo en aquellas obligaciones que sean más ejecutivas». Cada miembro de la Junta hablaría por su departamento. Se reduciría así el conflicto:

se excusen por este medio las contiendas y resentimientos que se tienen del Ministerio de Hacienda [...] porque, concurriendo todos a proponer la distribución del caudal, será el cuerpo unido de la Junta el que haga el repartimiento ${ }^{118}$.

Como consecuencia, se deben anular las consignaciones separadas: «deben quedar en libertad todos los efectos» dados a Marina, recogiéndose las cartas de pago ya emitidas, y no se debe hacer la consignación de Guerra. La mención del fondo de la Compañía de Guipúzcoa milita en el mismo sentido ${ }^{119}$.

115. Consulta de la junta de Hacienda, 04/01/1741. AHN, E, leg. 3149.

116. Consulta de la junta de Hacienda, 31/01/1741. AGS, SSH, leg. 399-1.

117. Consulta de la junta de Hacienda, 04/01/1741. AHN, E, leg. 3149.

118. Idem, nota 117-2. Consulta de la junta de Hacienda, 04/01/1741. AHN, E, leg. 3149.

119. Idem, nota 117-3. Consulta de la junta de Hacienda, 04/01/1741. AHN, E, leg. 3149.

Ediciones Universidad de Salamanca / @ه母: Stud. his., H. ${ }^{a}$ mod., 40, n. 1 (2018), pp. 427-460 
Los contornos de cada grupo son nítidos. Montemar y los dos Tenientes Generales presentes en la Junta ${ }^{120}$ se resisten a firmar la consulta de 4 de enero y solo lo hacen para plegarse al imperativo de pluralidad de los votos, dando votos separados a 7 y 8 de enero de 1741 . Montemar distingue lo que hace en tanto miembro de la Junta y en tanto Ministro de Guerra. Rechaza la propuesta de la Junta, arguyendo que en tales condiciones, arreciaría el conflicto. Además, una junta formada de miembros ocupados en otras actividades no se podría dedicar a su tarea. Finalmente, sería acabar con el Secretario del Despacho de Hacienda - valga la ironía. Los Tenientes Generales se disculpan de haber rubricado la consulta de 4 de enero, alegando que se equivocaron sobre las intenciones de Verdes Montenegro, pensando que si la Junta tenía la superintendencia, el infante devolvería las cartas de pago de buen grado. Pero ya que Verdes Montenegro quiere «tratar a la Marina a su arbitrio», la solución les parece inviable ${ }^{121}$. Verdes Montenegro denunciará su complicidad con Montemar ${ }^{122}$. Somodevilla abunda en el sentido de sus colegas: «de nada sirven las cartas de pago si al Ministro de Hacienda le queda la facultad de usar como hasta aquí de sus efectos»; las consignaciones dadas a Marina deben quedar «tan libres y (sic) independientes de la Hacienda que absolutamente ni su Ministro ni otro alguno pueda tocar a ella». Las cartas de pago ya recibidas, explica, fueron entregadas por orden del infante al marqués de Iturbieta, Arizcun, para que remitiera el dinero a las Tesorerías de Marina ${ }^{123}$. Se trata de volver al manejo independiente de Marina.

La primera respuesta es prudente. Verdes Montenegro explica que no renuncia a ninguna prerrogativa, porque la distribución toca al rey, correspondiendo las otras competencias (arrendar rentas, velar sobre su recaudación, resolver litigios) al Gobernador del Consejo de Hacienda ${ }^{124}$. Sin embargo, a 23 de enero, la Junta de Hacienda formula una propuesta más radical. Ya no habla solo de «conocimiento» de la «distribución de caudales». Solicita la Superintendencia de la Real Hacienda, precisando que implica la facultad para ella de convocar a los fiscales del Consejo de Hacienda, los Contadores Generales, el Superintendente del Tabaco y cualquier ministro dependiente de la Superintendencia, así como arrendadores, hombres

120. Torres no aparece, tal vez porque se le mandó al departamento marítimo del Ferrol desde junio (Fichoz).

121. Votos particulares de Montemar (07/01/1741) y Mari y Cornejo (08/01/1741). AHN, E, leg. 3149. «Extracto por mayor del expediente sobre consignaciones de Marina y del ejército de prevención», ¿por el secretario Masero?, enero de 1741. AGS, SSH, leg. 399-1.

122. Verdes Montenegro a Villarías, Madrid, 10/01/1741. AHN, E, leg. 3149.

123. Somodevilla a Villarías, Buen Retiro, 01/02/1741. AHN, E, leg. 3149.

124. «Extracto por mayor», AGS, SSH, leg. 399-1. Verdes a Villarías, Madrid, 10/01/1741. AHN, E, leg. 3149. 
de negocios y asentistas. Asimismo, el Tesorero General, la Pagaduría General de Juros y las demás oficinas que tienen manejos y dependen del Ministro de Hacienda se colocarían bajo la autoridad de la Junta, que prepararía los libramientos ${ }^{125}$. En un memorial adjunto del mismo día, Verdes Montenegro justifica su apoyo a esta propuesta. Su argumentación suena como una confesión:

\begin{abstract}
Señor. Siempre es y se ha considerado lo que la Junta propone a Vuestra Majestad de ser importante al real servicio que el fondo de la monarquía se gobierne por una sola mano y conocimiento, para que con reflexión a lo que haya que atender se comparta según la naturaleza de las obligaciones; y ninguno más propio que el de la Junta, pues aunque lo pueda ejecutar un solo Ministro celoso e inteligente, no tiene igual fuerza para que sean preferidas las más privilegiadas, mayormente en la situación actual [...]. Siendo bien de notar que, no habiendo más que un año que entré en estos manejos, me reconvengan sobre el todo de los débitos atrasados, como si con mi ingreso hubiese venido el oro que ha dado el Potosí, cuando es evidente que, como va expresado, no alcanza el erario con tan gran diferencia a cubrir el gasto anual y se convence no ser dable detener uno solo el ímpetu con que piden ser pagados los acreedores asistidos de su justicia y necesidad, pues, precisados de ella, se propasan con indocilidad irreflexiva a ciertas expresiones que, tocando en lo irreverente, ajan la autoridad que Vuestra Majestad concede y dejan bastantes señas del desacato ${ }^{126}$.
\end{abstract}

Dos motivos pesan en la decisión de Verdes Montenegro. Primero, reconoce haber perdido peso político como Ministro de Hacienda. No puede imponerse a los demás ministros ni resistir solo la presión de los acreedores, que deriva en falta de respeto. El segundo motivo es la convicción de que el mejor modo de organizar la distribución de caudales es hacerlo por «una sola mano y conocimiento». En cierta medida, acepta suicidarse políticamente para preservar el manejo único en la Tesorería Mayor. A pesar de su humildad, la carta evidencia la responsabilidad del rey en la situación presente, recordándole Verdes Montenegro que, al tolerar los insultos contra su Ministro de Hacienda, expone su propia autoridad.

Esta confesión acusatoria podría pesar en la decisión que toma el rey, en febrero, de destituir a Verdes Montenegro, sustituyéndolo por Campillo y dando a este las tres Secretarías del Despacho de Hacienda, Guerra, Marina e Indias. En efecto, la petición de auxilio del Ministro de Hacienda no despierta ninguna misericordia en el Secretario de Estado Villarías, por cuya vía Verdes Montenegro se dirige al rey. Después de la demanda de la Junta, la situación está bloqueada. El rey no contesta

125. «Extracto por mayor», AGS, SSH, leg. 399-1. Consulta de la junta de Hacienda de 23/01/1741. AHN, E, leg. 3149.

126. Verdes Montenegro al rey, 23/01/1741. AHN, E, leg. 3149. 
la propuesta de la Junta, aunque invita a Verdes Montenegro a poner en obra las resoluciones tomadas por las vías reservadas de Marina y Guerra ${ }^{127}$. Villarías, en las mismas fechas está negociando con Campillo, candidato al ministerio, y parece ya decidido a retirar su apoyo a Verdes Montenegro. Así, cuando este se niega a pagar un fondo reclamado por Somodevilla, Villarías explica que «se ha evadido» de aplicar la orden ${ }^{128}$. Verdes Montenegro se ve abandonado, lamentándolo en una nueva justificación de su actividad ${ }^{129}$. Una decisión de mediados de febrero confirma su sentimiento. El rey aprueba la oferta de los Gremios Mayores de arrendar las rentas de Madrid anticipando 15 millones de reales. La anticipación, se precisa, se remitirá a Arizcun «para que los distribuya según mis reales órdenes que le comunicare el marqués de Villarías, y no en otra forma» ${ }^{130}$. Se trata de otra consignación aparte, que se gastará en nombre del Tesorero General, pero sin intervención de Verdes Montenegro. A 25 de febrero, este recibe la orden de abandonar sus empleos. Sin duda se le quiere castigar: su solicitud de un título de Castilla, a imitación de Iturralde, no es oída ${ }^{131}$. En cuanto a la Junta de Hacienda, Campillo deja de consultarla ${ }^{132}$.

\section{Conclusión}

El episodio confirma el interés para los historiadores de adentrarse en el uso político y las formas de trabajo diarias de los órganos de gobierno de la Hacienda para entenderlos. En lo concerniente a la Tesorería General, el punto de partida fue la ambivalencia de una red de cajas concebida para hacer pagos en toda España mediante giros entre sus agencias locales, proporcionando al Ministro de Hacienda un conocimiento fiable del estado de la deuda corriente del rey -basado en la estimación del valor de los efectos de la Tesorería que quedaban sin pagar, pero susceptible de utilizarse de forma más ágil, organizándose el «beneficio» de los mismos efectos. El punto de llegada es la observación de que, sin modificar la planta de la Tesorería, es posible utilizar de formas diversas la unidad de la cuenta

127. Verdes Montenegro a Villarías, 31/01/1740. AHN, E, leg. 3149.

128. Verdes Montenegro a Villarías, Madrid, 26/01/1741. Villarías a Felipe V, 31/01/1740. AHN, E, leg. 3149.

129. "Las circunstancias del aviso de Vuestra Excelencia no dejan de hacerme creer dimanan de influencias que conducen a haber persuadido al rey que mi proceder no es el de mayor celo a su real servicio». Verdes Montenegro a Villarías, 31/01/1740. AHN, E, leg. 3149.

130. Felipe V a Joseph de Prado Güemes, El Pardo, 17/02/1741. AHN, E, libro 793.

131. Verdes Montenegro a Villarías, Madrid, 27/02/1741. AHN, E, leg. 2974.

132. Se conservan documentos de la junta posteriores al cese de Verdes Montenegro, pero ya no parece reunirse y Campillo aparta a Molina de la persecución judicial de Iturralde.

Ediciones Universidad de Salamanca / @ه母: Stud. his., H. ${ }^{a}$ mod., 40, n. 1 (2018), pp. 427-460 
que constituye su originalidad. Para Verdes Montenegro y Prado Güemes, esta unidad se asocia a la unidad del «manejo»; implica que corresponde al Ministro de Hacienda, asesorado por el Tesorero Mayor, arbitrar cada mes entre las prioridades del gasto, revisando las asignaciones previstas. Esto supone que en la ejecución de los estados de gasto y los cuadros de dotación formados desde el año anterior, el Ministro de Hacienda pueda arbitrar entre los departamentos de Guerra, Estado, Hacienda, Marina, Justicia. Para los responsables de Guerra, Marina y Casas Reales, nada impide crear, dentro de la propia Tesorería General, consignaciones particulares para departamentos privilegiados, que los usarán con autonomía, sin perjuicio de la cuenta única de la Tesorería. Para entender las disposiciones adoptadas, es preciso examinar las relaciones que los actores pretenden establecer entre la Tesorería General, los Ministros y los intendentes. En lo que concierne a la Junta de Hacienda, el examen de sus propuestas muestra que, a pesar de su forma colegial y de que la dirige el Gobernador de Castilla, tiene poco que ver con una «involución» favorable al poder de los Consejos; tampoco se propone inicialmente minar el poder del Ministro de Hacienda. Responde más bien al interés de su Presidente, deseoso de recuperar protagonismo y tal vez defender sus negocios en la Cruzada, así como a una estrategia política de control del Ministro de Guerra.

El episodio también es aleccionador para sus protagonistas. Se plantean de forma aguda dos problemas políticos, más que financieros. El primero no es una originalidad española. Es la rivalidad entre los responsables de los departamentos más dispendiosos con el Secretario de Hacienda ${ }^{133}$. Detrás de ella, está la cuestión del papel del rey y la reina. Aunque pudieron apoyar reformas tendentes a consolidar la posición preeminente del Ministro de Hacienda en la distribución de caudales, no hacen de ello una cuestión de principio, sino que parecen querer preservar, ante todo, su propio margen de maniobra para ejercer la gracia ${ }^{134}$. Huelga decir que sería deseable conocer mejor el arbitraje de los monarcas o de sus personas de mayor confianza entre los proyectos defendidos por diversos grupos de poder en su corte, en lo que concierne al gobierno de la Hacienda, para comprender las sucesivas reorientaciones que se dan durante el reinado de Felipe V. El segundo problema que aflora en la crisis de 1740 es la fragilidad de la Tesorería General y del Ministro de Hacienda frente a la presión de unos acreedores que, como lo reconoce la Junta de Hacienda, no se limitan al puñado de hombres de negocios que dan la cara en los contratos, sino que podrían confundirse con parte de las élites

133. Se observan conflictos comparables en la Francia del siglo XviIr. Legay, M. L. L.: La banqueroute de l'État royal. La gestion des finances publiques de Colbert à la Révolution française. París, Éditions de l'École des Hautes Études en Sciences sociales, 2011.

134. Vázquez Gestal: Una nueva..., p. 314. 
económicas y políticas de la corte que les confían sus ahorros, a las que tendríamos que identificar con mayor precisión. Aunque solo sea por plantear estos dos problemas, los meses del ejercicio de Verdes Montenegro no se pueden reducir a un mero paréntesis en la historia de las reformas del gobierno de la Hacienda. El empate a que se llega a fines de 1740 obliga a buscar formas institucionales para resolver el conflicto entre los responsables y restaurar la confianza del mundo del crédito. Campillo y Ensenada, testigos y partícipes del fracaso político de Verdes Montenegro, tendrán que acometer estas tareas.

\section{Abreviaturas}

AHN: Archivo Histórico Nacional.

E: Estado.

FC-MH: Fondos contemporáneos, Ministerio de Hacienda.

AGS: Archivo General de Simancas.

SSH: Secretaría y Superintendencia de Hacienda.

BNE: Biblioteca Nacional de España.

\section{Bibliografía}

Abbad, F. y Ozanam, D.: Les intendants espagnols du Xville siècle, Madrid, Casa de Velázquez, 1992.

Andújar Castillo, F:: «La hacienda real en tiempos de crisis: 1739-1741», en Cortés Peña, A.L., López-Guadalupe Muñoz, M.L., SÁnchez-Montes González, F. (eds.), Estudios en homenaje al profesor José Szmolka Clares. Granada, 2005, pp. 537-546.

Aquerreta, S.: Negocios y finanzas en el siglo XVIII: la familia Goyeneche. Pamplona, EUNSA, 2002.

Burgos Lejonagoitia, G.: Gobernar las Indias. Venalidad y méritos en la provisión de cargos americanos, 1701-1746. Almería, Universidad de Almería, 2015.

Caro Baroja, J.: La hora navarra del XVIII (personas, familias, negocios e ideas), Pamplona, Comunidad Foral de Navarra, 1985, $1^{a}$ ed. 1969.

Castro, C. de: El Consejo de Castilla en la historia de España (1621-1760). Madrid, Centro de Estudios Constitucionales, 2015.

Cruz Mundet, J. R.: «Iturralde y Gamio: un asentista navarro en la corte de Felipe V», Principe de Viana, 255, 2012, pp. 205-260.

Dedieu, J. P.: «La Nueva Planta en su contexto. Las reformas del aparato del Estado en el reinado de Felipe V», Manuscrits, 18, 2000, pp. 113-139.

Dedieu, J. P.: Après le roi. Essai sur l'effondrement de la monarchie espagnole. Madrid, Casa de Velázquez, 2010.

Dedieu, J. P.:, «Les groupes financiers et industriels au service du roi - Espagne. Fin xvire - début xvirie siècle», en Dubet, A. y Luis, J. P. (eds.): Les financiers et la 
construction de l'Etat en France et en Espagne (milieu du XVIIe siècle-milieu du XIXe siècle). Rennes, PUR, cap. 5.

Dedieu, J. P.: «Fichoz 2011. Balance de una base de datos sobre la España moderna», en Jiménez Estrella, A., Lozano Navarro, J., Sánchez Montes, F., Birriel Salcedo, M. M. (eds.): Construyendo historia. Estudios en torno a Juan Luis Castellano, Editorial de la Universidad de Granada, 2013, pp. 185-200.

Delgado Barrado, J. M.: Aquiles y Teseos. Bosquejos del reformismo borbónico (17011759), Universidad de Granada, Universidad de Jaén, 2007.

Dessert D.: Argent, pouvoir et société au Grand Siècle. París, Fayard, 1984.

Dubet, A.: La Hacienda Real de la Nueva Planta (1713-1726), entre fraude y buen gobierno. El caso Verdes Montenegro y las reformas de la Hacienda, Fondo de Cultura Económica, Madrid, 2015.

Dubet, A.: «El gobierno de la Hacienda real de Felipe V y los interesados según Alejandro de Vega», Tiempos Modernos, núm. 30, 2015/1. http://www.tiemposmodernos.org/ tm3/index.php/tm/article/view/430/461

Dubet, A.: «Entre razón y ciencia de la Hacienda: la conflictiva construcción de un modelo de buen gobierno de la Real Hacienda en España en la primera mitad del siglo XviII», Espacio, Tiempo y Forma, 2015, núm. 28, 2015, pp. 187-209. http://revistas.uned.es/ index.php/ETFIV/article/view/14204/13605.

Dubet, A.: «La suspensión de pagos de 1739: ¿una medida de «buen gobierno» de la Hacienda?», Espacio, Tiempo y Forma, 30, 2017, pp. 19-56. http://revistas.uned.es/ index.php/ETFIV/issue/view/1079.

Dubet, A.: «Entre servicio del rey y tráfico de efectos: la doble negociación de Juan Bautista de Iturralde», Librosdelacorte.es, n 13 , Otoño-invierno 2016. ISSN 1989-6425. URL: https://revistas.uam.es/librosdelacorte/article/view/7041/7410.

Escobedo Romero, R.: El tabaco del rey. La organización de un monopolio fiscal durante el Antiguo Régimen. Pamplona, EUNSA, 2007.

Fernández Albaladejo, P.: «El decreto de suspensión de pagos de 1739: análisis e implicaciones», Moneda y crédito, 142, 2007, pp. 51-85.

Gallardo Fernández F.: Origen, progreso y estado de las rentas de la corona de España, Madrid, Imprenta Real, 1805-1808.

Garzón Pareja, M.: «La renta de población del reino de Granada», Cuadernos de la Alhambra, 18, 1982, pp. 207-229.

Giménez López, E.: «El debate civilismo-militarismo y el régimen de Nueva Planta en la España del siglo xviII». Cuadernos de Historia Moderna, 15, 1994, pp. 41-75.

González Enciso, A. (ed.): Navarros en la Monarquía española en el siglo XVIII, Pamplona, EUNSA, 2007.

GonzÁlez Enciso, A.: «Lenta recuperación y consolidación. La renta a mediados de siglo, 1740-1760», en González Enciso, A. (ed.): Política económica y gestión de la renta del tabaco en el siglo XVIII. Madrid, Los libros de Altadis, 2008, pp. 175-210.

GonzÁlez EnCISO, A.: «Empresarios navarros en la industria de municiones para la artillería», en Torres SÁnchez, R. (ed.): Volver a la hora navarra, 2010, pp. 158-211.

Ediciones Universidad de Salamanca / @ه母: Stud. his., H. ${ }^{a}$ mod., 40, n. 1 (2018), pp. 427-460 
Guerrero Elecalde, R. e Imízcoz Beunza, J. M.: «Familias en la monarquía. La política familiar de las élites vascas y navarras en el Imperio de los Borbones», en ImÍzcoz Beunza, J. M. (ed.): Casa, familia y sociedad (País Vasco, España y América, siglos $X V-X I X)$. Bilbao, Universidad del País Vasco, 2004, pp. 177-238.

IÑurritegui Rodríguez, J. M.: Gobernar la ocasión. Preludio politico de la Nueva Planta de 1707, Madrid, Centro de Estudios Políticos y Constitucionales, 2008.

Legay, M. L. L.: La banqueroute de l'État royal. La gestion des finances publiques de Colbert à la Révolution française. París, Éditions de l'École des Hautes Études en Sciences sociales, 2011.

Muñoz Rodríguez, J. D.: «El superintendente austriaco y el intendente borbónico. La evolución de un modelo de gestión de los recursos fiscales en la Monarquía hispánica», en Dubet, A. y Ruiz IBÁÑez, J. J. (eds.): Las monarquías española y francesa (siglos XVI-XVIII). ¿Dos modelos políticos? Casa de Velázquez, 2010, pp. 130-141.

Peralta Ruiz, V.: Patrones, clientes y amigos. El poder burocrático indiano en la España del siglo XVIII. Madrid, CSIC, 2006.

Quirós Rosado, R.: «Las secretarías de Estado y Guerra en la monarquía de Carlos VI: ¿vías hacia una planta ejecutiva?», en Pérez Álvarez, M. J. y Martín García, A. (eds.): Actas de la XI reunión científica de la FEHM, Granada, Universidad de Granada, 2012, pp. 1581-1592.

Rodríguez Villa, A.: Patiño y Campillo. Madrid, Sucesores de Rivadeneyra, 1882.

Solbes Ferri, S.: «El control del gasto de la Marina española en las Secretarías de Estado y del Despacho. Los pagos dependientes de la Tesorería General en la primera mitad del XVIII», en BAUDOT, M. (ed.): El Estado en guerra. Expediciones navales españolas en el siglo XVIII, Madrid, Polifemo, 2014, pp. 147-194.

Solbes Ferri, S.: «El delicado tránsito entre recaudación de rentas y ejecución del gasto. La renta del tabaco y la Tesorería General a mediados del siglo XVIII», en prensa.

Torres SÁnchez, R.: «Los navarros en la provisión de víveres a la Armada española durante el siglo XVIII», en Torres SÁnchez, R. (ed.): Volver a la hora navarra, 2010, pp. 213-262.

Torres SÁnchez, R.: «La militarisation des finances royales d'Espagne au Xvirie siècle», en Dubet, A. y Luis, J. P. (eds.): Les financiers et la construction de l'Etat en France et en Espagne (milieu du XVIIe siècle-milieu du XIXe siècle). Rennes, PUR, 2011, cap. 9, pp. 177-198.

Torres SÁnchez, R. (ed.): Volver a la "hora navarra». La contribución navarra a la construcción de la monarquía española en el siglo XVIII. Pamplona, EUNSA, 2010.

Vázquez Gestal, P.: Una nueva majestad. Felipe V, Isabel de Farnesio y la identidad de la monarquia (1700-1729). Madrid, Marcial Pons, 2013.

Zuluaga Cítores, A.: Sebastián de la Quadra, Secretario de Estado en el reinado de Felipe V, primer marqués de Villarias (1687-1766). Santander, 1999.

Ediciones Universidad de Salamanca / @ه尺@ Stud. his., H. ${ }^{a}$ mod., 40, n. 1 (2018), pp. 427-460 